\title{
Silicon Quantum Dots for Photovoltaics: A Review
}

\author{
Georg Pucker, Enrico Serra and Yoann Jestin \\ Bruno Kessler Foundation, Center for Materials and Microsystems,
}

Italy

\section{Introduction}

Controlling size and shape of materials on the nanoscale allows to engineer their physical properties. Indeed nanomaterials offer unique opportunities in engineering, microelectronics, life-science, and renewable energies. Conversion of sunlight to electricity is assumed to be of major importance for the supply of electrical energy for future generations. The actual photovoltaic market is dominated by silicon solar cells. However, to address future needs in electricity in the order of $\sim 30$ Terawatts, the cost of solar energy will have to be significantly lower and the efficiency will have to be increased significantly with respect to actual values. With these preconditions it is understandable that the interest in exploring the properties of silicon nanostructures in solar cells is enormously increased. Especially, since for silicon, a similar revolution already happened regarding the shrinkage of the size of transistors accompanied by an exponential increase in speed. The review summarizes the most important properties of silicon quantum dots (Si-QDs), gives an overview of solar cell concepts, in which Si-QDs can play a role and indicates major achievements to be envisioned for another technological revolution based on silicon technology.

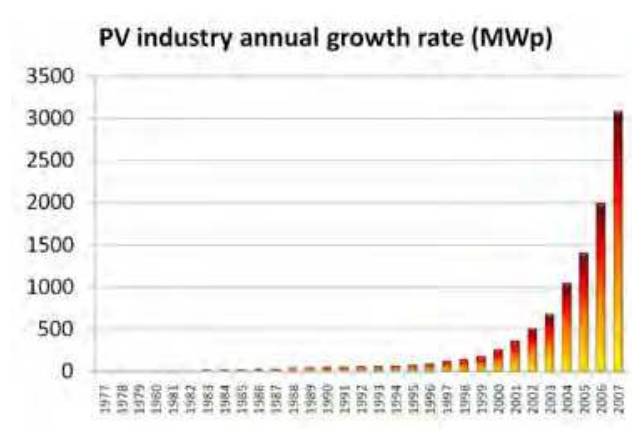

(a)

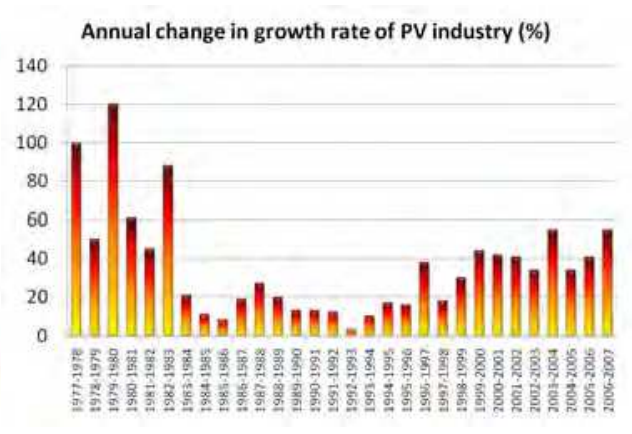

(b)

Fig. 1. a) Photovoltaic industry annual growth (1977-2007), b) annual change in growth rate (data from (Marketbuzz, 2010)). 


\subsection{Current trends in photovoltaics}

Since over 2 decades the photovoltaic market shows an exponential growth with annual growth rates in the range of $40-50 \%$ (Hirshman et al., 2007). It took, however, more than hundred years, since the discovery of the photovoltaic effect by Edmond Becquerel (Becquerel, 1867) in 1839, until the $1^{\text {st }}$ viable commercial demonstration of a solar cell. These c-Si based solar cell invented in 1954 by researchers at Bell laboratories had an efficiency of $\sim 4 \%$ (Chapin et al., 1954). Only after the oil crisis of the 1970s photovoltaic energy was considered as an alternative source of electricity. The rapid exponential growth of cumulative installed capacity, which occurred in the last 2 decades is illustrated in Fig.1. Indeed world solar photovoltaic (PV) market installations reached a record high of 7.3 gigawatt (GW) in 2009, representing growth of $20 \%$ over the previous year (Marketbuzz, 2010). Although, PV electricity can't yet compete directly with electricity from conventional sources on the wholesale or retail prices, it is already competitive during peak power times (Wolfsegger \& Stierstorfer, 2007), and it is expected to reach grid parity with retail prices in Southern Europe before 2015 and in most of Europe by 2020 (European Photovoltaic Technology Platform, 2007). Current photovoltaic technology is dominated by silicon.

\section{Photovoltaic technology market share (\%)}

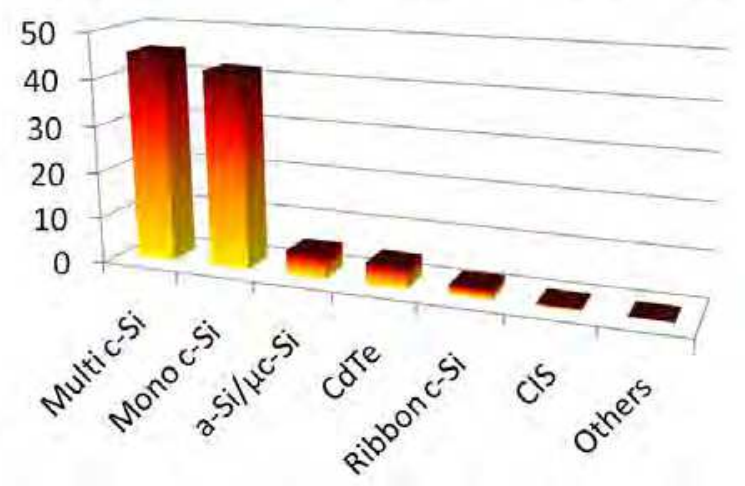

Fig. 2. Market share of photovoltaic technology (Teske \& Bitter, 2008).

Figure 2 shows the market share of PV technology (Teske \& Bitter, 2008). The overwhelming part of the market is based on crystalline silicon $\sim 85 \%$ (including both large grain multicrystalline [multi cSi] and mono-crystalline [mono cSi] materials). These solar modules based on silicon wafers, either multi-crystalline or mono-crystalline, have been termed "first generation" photovoltaic technologies. The devices are based on a fairly simple p-n junction and have a thermodynamic efficiency limit of $\sim 30 \%$ (Shockley \& Queisser, 1961) (taking into account the shape of the solar cell, the refractive index of the cell, realistic solar spectrum, concentration, and radiative recombination) - this limit is often called Shockley-Queisser limit. Best laboratory c-Si solar cells arrive at an efficiency of about $25 \%$ (Green et al., 2010) with highest efficiencies for modules of $\sim 21.4 \%$ (Sunpower Corp.), while efficiencies for most of the commercial c-Si modules on the market are in the range 16-20\%. A second class of solar cells "2nd generation" attempts to reduce costs by using thin film semiconductors like amorphous silicon $(\mathrm{a}-\mathrm{Si}), \mathrm{CdTe}, \mathrm{Cu}(\mathrm{In}, \mathrm{Ga}) \mathrm{Se}_{2}$ with about $\sim 14 \%$ of market share and cell 
efficiencies in the range $10-20 \%$ depending on the system. In addition, in the same class of cells fall dye-sensitized solar cells (DSSC) and organic photovoltaic cells (OPV) based on conducting polymers and fullerenes. DSSCs introduced by M. Grätzel and co-workers in 1991 (O'Regan, \& Grätzel, 1991), are based on a concept of light harvesting and charge separation similar to the one known from nature in photosynthesis. Best DSSCs have an efficiency of $\sim 10-12 \%$ (Green et al., 2010). Current most efficient dye-sensitized cells make use of ruthenium organic complexes and liquid electrolytes. The use of ruthenium-organic complexes is critical for large scale production due to the high cost and low abundance of ruthenium, while the use of liquid-electrolytes for carrier transport reduces lifetime of the modules because of corrosion and evaporation of electrolyte. Therefore, intense research is performed on the use of alternative dyes and solid-state electrolytes (Wei et al., 2010). OPV cells consist of a mixture of small organic molecules and polymers structured on the nanometer scale. Light absorption results in the formation of excitons, which are subsequently separated at the interfaces of the distinct organic materials working as electron acceptors or donors, respectively. The created charges diffuse then eventually to the electrodes and are collected in the external circuit. The organic molecules and polymers used are inherently inexpensive and cells are rapidly increasing in efficiency. OPV cells can be produced on flexible substrates with large throughput by low-cost roll to roll processing (Brabec et al., 2008). Efficiencies of OPV cells rapidly increased and highest reported efficiencies are $\sim 8 \%$ (Solamer Inc., Konarka Technologies). One key issue for the success of OPV is device degradation caused by oxygen or water. Development of encapsulations that are stable for 10-25 years will be a significant challenge.

\subsection{Scenario of future photovoltaics}

The market for photovoltaic technology - mainly based on silicon - showed exponential growth rates in the last twenty years, and manufacturing costs of silicon based solar models in the range of $\sim 1 \$ / W_{p}$ should be achieved in the near future (Del Cañizo et al., 2009). With an estimate of about $\sim 40 \mathrm{GW}$ of electricity produced by solar photovoltaic power for the year 2010 the contribution to worldwide electricity generation is still negligible, if compared with the average total worldwide power consumption of 15 Terawatts (TW). Capturing and transforming in electrical power even a small fraction of the 122,000 TW of energy from the sun could give a significant contribution to present and future power generation. According to (Feltrin, \& Freundlich, 2008) it is expected that between 2050 and 2070 fossil fuels (gas, oil and coal) will play a minor role for energy production and, even projecting a robust growth of nuclear and wind energy, solar power generation should play an important role. Scaling current photovoltaic technologies from present gigawatt energy production up to the terawatt range, which means that the energy production by photovoltaics has to increase by nearly 3 orders of magnitude. For this reason abundancy of materials and materials shortage will play a more important role than in current photovoltaics. Nearly all of the current photovoltaic technologies are based on materials, which will be severely affected by material shortage. In the following we give some examples: Indium, which is currently widely used in touch screens and in photovoltaics i.e. in a-Si, DSSC, and organic solar cells as electrode material and in multi-junction cells as active material; silver and gold are used as electrode materials, germanium and gallium find application in multi-junction cells, and tellurium is used as cell material in CdTe solar cells. Interestingly, in another study, which considered the materials availability their material extraction costs, and the annual electricity potential, 
only a limited number of poorly investigated materials like $\mathrm{FeS}_{2}, \mathrm{CuO}_{2}$, and $\mathrm{Zn}_{2} \mathrm{P}_{3}$ were considered favorable with respect to a-Si solar technology for TW photovoltaics (Wadia et al., 2009). The problem of materials availability together with the still too large costs of power generation of most photovoltaics technologies has led to search for a new generation of cells ( $3^{\text {rd }}$ generation photovoltaics), aiming at the same time to keep the costs/Watts as low as possible and to push the cell efficiency significantly over the Shockley-Queisser limit of $30 \%$ for single junction solar cells. A series of different concepts and physical phenomena are currently investigated for this purpose: tandem and multi-junction cells, hot-carrier cells, up-and down conversion processes, etc.

\subsection{Why silicon quantum dots for solar cells?}

Si-QDs differ in a series of properties considerably from bulk silicon: i) Si-QDs show an increase in the energy gap with shrinking dimensions of the dot. Therefore by controlling the size it is in principle possible to shift the energy bandgap of the material to the optimum energy gap (i.e. $1.6 \mathrm{eV}$ ) for maximum efficiency of single junction solar cells, or to stack cells with different bandgap and hence different spectral response together to form tandem cells. ii) Si-QDs show strong photoluminescence in the visible-red region of the solar spectrum and external quantum efficiencies as high as $60 \%$ were reported in literature. This strong photoluminescence can be used in photoluminescence downshifters to increase the efficiency. iii) in quantum dots due to the widening of the distance between the energy states the relaxation of excited carriers is slowed down with respect to bulk silicon. If the carriers can be extracted from the dot before relaxing to the edge of the band gap, one could increase the open circuit voltage of the solar cells. This idea is explored in the concepts for hot carrier solar cells. iv) another phenomena, which is investigated for use in solar cells is the generation of multiple excitons in silicon quantum dots. An exciton with an energy much larger than the bandgap (at least twice), has an increased probability to split into ' $n$ ' excitons instead of losing the excess energy in form of heat and relaxing to the edge of the bandgap. These multiple excitons, if extracted successfully from the dot, would lead to an increased current of the solar cell, or if both multiple excitons recombine radiatively the material would show an increased photoluminescence quantum efficiency. The review is organized in the following way: in the $1^{\text {st }}$ section we give a brief summary on the properties of Si-QDs focusing especially on the properties relevant for use in solar cells such as band-gap opening, photoluminescence properties, electrical transport etc. (an enormous amount of research was done in this field since the observation of strong photoluminescence from porous silicon in 1990 (Canham, 1990) and a series of excellent books and reviews are available for the interested reader (Amato et al., 1997; Cullis et al., 1997; Canham, 2007), while in the $2^{\text {nd }}$ part we present a series of ideas and concepts, which aim on the realization of solar cells based on silicon quantum dots. Some of these concepts were already successfully demonstrated with other type of semiconductors. For example tandem cells consisting of stacked solar cells with each cell harvesting a different portion of the solar spectrum, but they rely on relatively rare elements like Ga, In, or As and will therefore not play a significant role for the generation of TW of electrical energy from sun light. Other concepts like hot-carrier cells are very promising in terms of their high thermodynamic efficiency limit $(\sim 85 \%)$, but no hot carrier-solar cell has been fabricated so far. Experimental research in this field therefore concentrates on the study of hot carriers in 
different bulk and quantum confined semiconductors and on the development of energy selective contacts for carrier extraction.
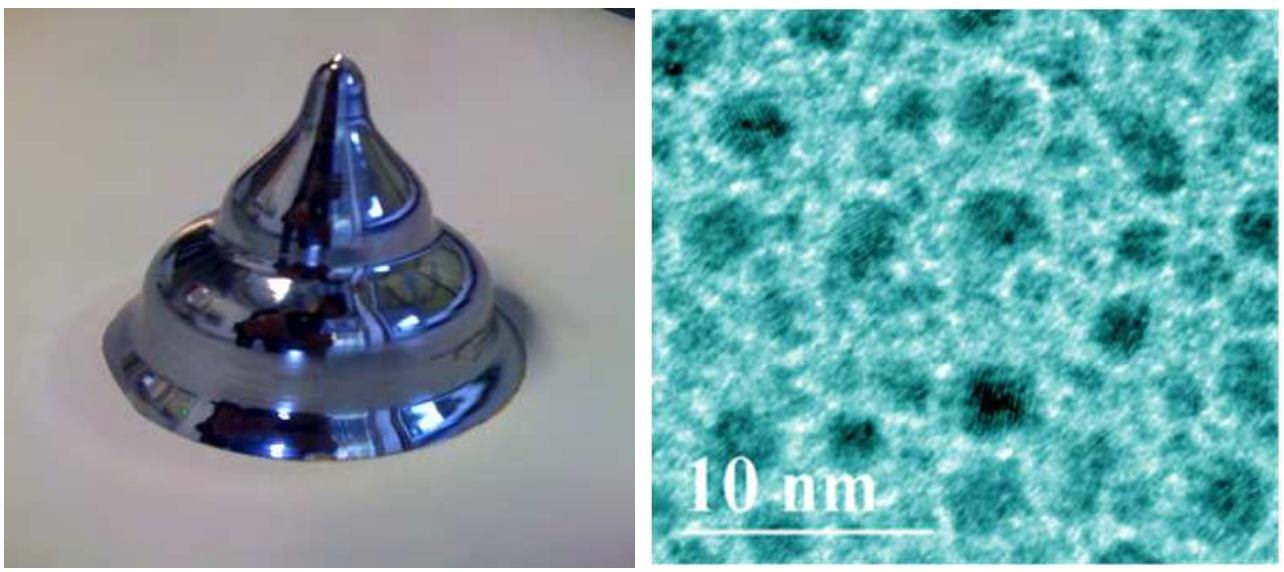

Fig. 3. (left) Upper part of an ingot of single crystalline silicon. The diameter of the ingot shown in the photograph is $100 \mathrm{~mm}$. Largest silicon ingots grown by the Czrochalski method have a diameter of $30 \mathrm{~mm}$ and a length of $\sim 2 \mathrm{~m}$. (right) HRTEM image of tiny silicon quantum dots in a $\mathrm{SiO}_{2}$ matrix. Si-dots appear as dark structures and the (111) lattice plans are clearly seen. The dimension of the Si-quantum dots shown in the image is between 2 and $5 \mathrm{~nm}$.

\section{Properties of silicon quantum dots}

\subsection{Optical properies}

In Figure 3 a piece of a silicon single crystal ingot with a diameter of $10 \mathrm{~cm}$ and a high resolution TEM image of tiny silicon nanocrystals embedded in $\mathrm{SiO}_{2}$ with dimensions of about 2-4 $\mathrm{nm}$ are shown. While the properties of crystalline silicon can be considered uniform for dimensions ranging from some tenths of nanometers up to centimeters, the properties of Si-QDs as we will see in the following are (i) strongly dependent on size, (ii) influenced by the properties of the interface between QDs and matrix and (iii) the electrical transport in the material depends strongly on the distance between the QDs. For a better understanding of the properties of Si-QDs, it is useful to remember some of the fundamental properties of silicon. In the crystalline phase silicon forms a diamond structure. In this structure every silicon atom is surrounded by four nearest neighbour atoms forming a tetrahedron. The unit cell of silicon consists of 8 atoms and the lattice constant " $a$ " is 0.543 $\mathrm{nm}$. Due to the small distance of the atoms in the solid state the energy levels of the atoms overlaps and causes the formation of bands. The outermost electrons form two bands referred as the valence and the conduction band. At zero degrees Kelvin the valence band is completely filled with electrons and the conduction band is completely empty of electrons. A forbidden gap (band gap) separates the conduction from the valence band. For silicon this bandgap is of $1.12 \mathrm{eV}$ (or $\sim 1107 \mathrm{~nm}$ ) at room temperature. Silicon is an indirect band gap semiconductor, which means that the bottom of the valence band and the top of the conductance band are not aligned in-k space (see the electronic band structure of silicon based on $\mathrm{k} \cdot \mathrm{p}$ calculations in Figure 4). 


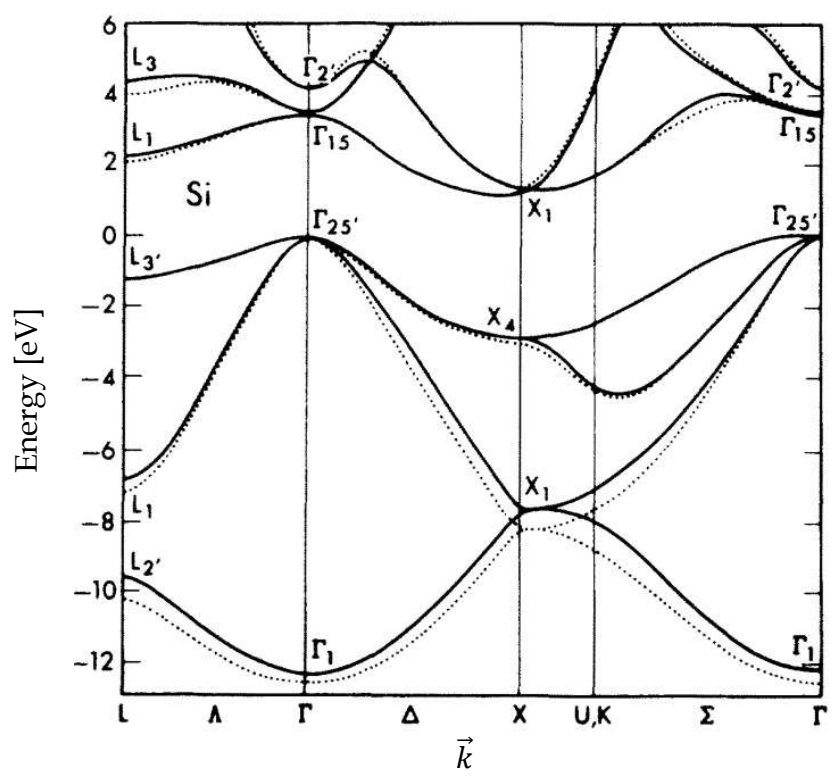

Fig. 4. Theoretical band structures of $\mathrm{Si}$. In the case of $\mathrm{Si}$, results are shown for nonlocal (solid line) and local (dashed line) pseudo-potential calculations (Chelikowsky \& Cohen, 1976). Reprinted figure with permission from [Chelikowsky, J.R.; Cohen, M.L. Physical Review B, Vol.14, pp. 556-582, 1976. Copyright (1976) by the American Physical Society].

The maximum of the valence band is at the Brillouin zone center or $\Gamma$ point (at $k=0)$, while the minimum of the conduction band is close to the $X$ point $(k \neq 0)$ at the Brillouin zone boundary. Since optical transitions conserve both energy and momentum the excitation of an electron from the top of the valence band to the bottom of the conduction band can occur only via the assistance of another process to conserve the momentum. In pure silicon this occurs via the transfer of the electron momentum to a phonon (the transition is therefore called indirect and the absorption close the band edge is very low, which can be nicely seen from the absorption coefficient $\mathrm{k}$ in Figure 5 (left). For the same reason the probability of relaxation of an excited electron from the conduction band to the valence accompanied by the spontaneous emission of a photon is low and radiative lifetimes in silicon as long as milliseconds can be observed. The absorption increases at higher energies due to the onset of the lowest energy direct transitions. The absorption reaches a first maximum at $359 \mathrm{~nm}$ assigned to the $\mathrm{E}_{1}$ transition, a strong maximum at $296 \mathrm{~nm}$ due to the $\mathrm{E}_{0}$ transition and another weaker maximum at $225 \mathrm{~nm}$ assigned to the $E_{1}^{\prime}$ transition. Figure 5 (right) shows the absorption edge of silicon, where structures can be identified as exitonic transitions. An exciton is formed due to the interaction of the excited electron in the conduction band with the remaining electrons (hole in the valence band). Due to the indirect nature of the edge also excitonic transitions become partially allowed through absorption or emission of phonons and the related transitions are seen as sharp structures in the absorption spectrum (Absorption edge of c-Si measured at $1.8 \mathrm{~K}$ from (Shaklee \& Nahory, 1970). The exciton binding energy in bulk silicon is relatively small $(\sim 15 \mathrm{meV})$. If we reduce the dimensions of 
a semiconductor like silicon in one, two or three dimensions on nanometric scale the properties of the material will be influenced by the spatial confinement i.e. the energy states of the electrons and holes lose their continuity and become discrete. Therefore, the absorption and emission of light when electrons or holes move from one state to another are affected. Nanostructures are often classified according the number of dimensions in which carriers (electrons) are free to move in 0-D (nanocrystals, quantum dots, porous silicon), 1-D (quantum wires and pillars), and 2-D (quantum wells).
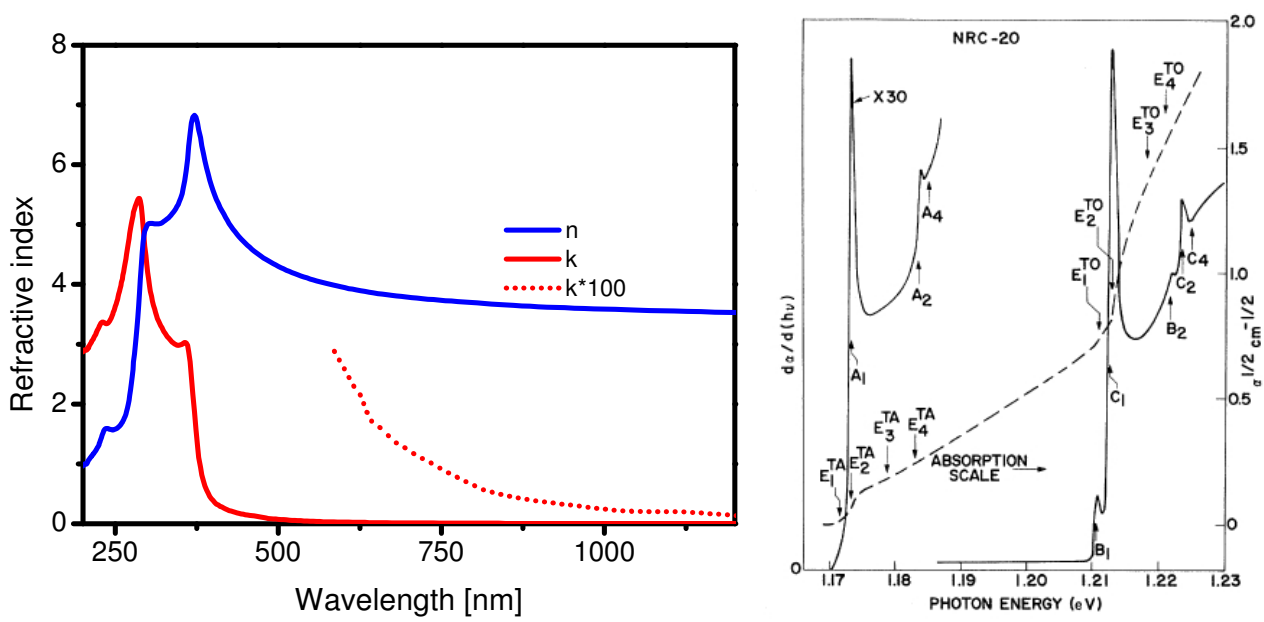

Fig. 5. Experimental dielectric function of $\mathrm{Si}$ (blue - real part of the refractive index, red imaginary part (or absorption coefficient) (left). Absorption edge of c-Si measured at $1.8 \mathrm{~K}$ from (Shaklee \& Nahory, 1970). Reprinted figure with permission from [Shaklee, K.L. \& Nahory, R.E. Physical Review Letters, Vol.24, pp. 942-945, 1970]. Copyright (1970) by the American Physical Society.

In the following, we will concentrate mainly on results obtained on 0-D silicon quantum structures, although silicon quantum-wires and quantum wells are very similar in their properties and a series of interesting and encouraging results for use in solar cells were especially obtained on silicon quantum wires (Tsakalakos et al., 2007; Kelzenberg et al., 2010). One of the fundamental effects of the confinement is its influence on the electronic properties of the system especially on the energy of the band gap. A simple estimation of the effect of the confinement on the energy of the electron gap $E_{\text {gap }}$ can be obtained by using the effective-mass approximation,

$$
E_{\text {gap }}=E_{S i_{-} \text {bulk }}+\frac{\hbar^{2} \Pi^{2}}{2}\left[\frac{1}{L_{x}^{2}}+\frac{1}{L_{y}^{2}}+\frac{1}{L_{z}^{2}}\right]\left[\frac{1}{m_{e}^{*}}+\frac{1}{m_{h}^{*}}\right]
$$

Where $E_{\text {Si_bulk }}$ stands for the energy gap in bulk silicon $(1.12 \mathrm{eV}), \mathrm{L}_{\mathrm{x}}, \mathrm{L}_{\mathrm{y}}, \mathrm{L}_{\mathrm{z}}$ are the dimensions of the nanoparticle and $m_{e}^{*}$ and $m_{h}^{*}$ are the effective electron and hole masses in bulk silicon. In a first approximation the hole mass is essentially half of the electron mass, the simple theory predicts that the valence band should shift twice the shift of the conductance band. In Figure 6 the increase of the energy gap for shrinking size of silicon quantum structures is shown (Lockwood et al. 1992). From the figure we can see that an 
appreciable effect on the energy gap is observed for Si-QDs smaller than $5 \mathrm{~nm}$ and for dots of $2 \mathrm{~nm}$ of size the gap is predicted to be as large as $\sim 2 \mathrm{eV}$. The shifts of the conduction and valence bands can be experimentally observed in x-ray absorption techniques and confirmed with good approximation the shifts of conduction and valence band foreseen from the effective mass approximation (Lockwood et al., 1996). In addition to changing bandgap energy the quantum confinement influences also the transition probabilities. Due to the localisation of the carriers (excitons) in a very small volume the $\mathrm{k}$ selection rules are relaxed and the transition probabilities are increased (quasi direct transitions). A lot of the early work on silicon nanocrystals was performed on porous silicon. Porous silicon discovered more than 50 years ago (Uhlir, 1956) is obtained typically by electrochemical etching of bulk silicon with HF. The porosity can range in dimensions from nanometers to micrometers and under correct etching conditions a spongy material with wall dimensions of a few nanometers can be obtained. In 1990 intense visible photoluminescence was observed from porous silicon (Canham, 1990) and the luminescence was ascribed to quantum confinement effects (Cullis \& Canham, 1991). In the following years intense research on porous silicon was performed, for application in silicon photonics and sensing. These research is reviewed in a series of books (Amato et al., 1997; Bisi et al., 2000; Canham, 2007; Feng \& Tsu, 1994). Highly porous silicon has an enormous surface area, which is available for interacting with the ambient either by chemical reactions or physisorption of molecules. For example oxidation of porous silicon tends to continue for weeks at room temperature, if the surface is not accurately passivated. In addition, due to the porosity the material is also mechanically instable and fragile. For this reason the scientific community looked for alternative methods to prepare better passivated and mechanically more stable Si-QDs. Nowadays a wide spectrum of fabrication techniques exists which allows to form Si-QDs in a gas phase, in solution or in solid state. Common to most of the fabrication methods is that the silicon quantum dots show a certain variation in size and shape. As an example we show in Figure 7 the absorption coefficient and the photoluminescence spectra of silicon quantum-dots obtained by thermal annealing of a silicon rich silicon oxide film (silicon rich or excess of silicon means that the film contains an excess of silicon with respect to the ratio of 1: 2 between $\mathrm{Si}$ and oxygen in stoichiometric silicon dioxide). In this type of measurements due to the dimensions of the light spot and the large density of silicon quantum dots a huge number of quantum dots is measured at the same time $\left(\sim 10^{11}\right.$ quantum-dots in the photoluminescence and about $\sim 10^{12}$ Quantum-dots in the ellipsometric measurements from which the absorption coefficients were obtained). The critical points of energy transitions, which are well defined in the absorption spectrum of c-Si (for example the E1 transition at $3.395 \mathrm{eV}$ ), are broadened and poorly defined due to this averaging over an enormous number of slightly different silicon quantum dots. The absorption coefficient increases with increasing silicon content ( $\Gamma$-value, which refers to the ratio of the gases $\mathrm{SiH}_{4}$ and $\mathrm{N}_{2} \mathrm{O}$ used during the deposition of the films). The photoluminescence spectra measured at room temperature of these samples show a broad photoluminescence band in the VISNIR region, which shifts from 800 to $850 \mathrm{~nm}$ for decreasing silicon content. This type of behaviour is reported by numerous studies and only some of them are cited here (Rinnert \& Vergnat, 2003; Umezu et al., 2000; Yang et al.,1997; Pucker et al., 2000).

Further inside in the structure of $\mathrm{Si}$ quantum dots comes from the analysis of photoluminescence (PL) decay curves. Similar to what is found in porous silicon the PL decay shows a dispersion in decay lifetime not only as function of emission wavelength, but also for a fixed wavelength. The decay curves are influenced by the dispersion in size and shape of the 
nanocrystals resulting in different radiative transition probabilities and by migration and trapping of excitons. Decay times at room temperature are typically in the range of 10 to $300 \mu \mathrm{s}$ (Linnros et al., 1999; Wilson et al., 1993) and the decay time increases up to milliseconds for low temperatures (<20 K) (Dovrat et al., 2004; Brongersma et al., 2000; Vinciguerra et al., 2000). The temperature dependence of the photoluminescence decay curves can be explained (Calcott et al., 1993) by ascribing the luminescence to the recombination of strongly localised excitons in the Si quantum dot. Due to the exchange interaction between the electron and the hole, the excitonic levels are split by an energy $\Delta$. The lower level corresponds to a triplet state (threefold degenerate), while the upper state is a singlet state. The ground state of the exciton is a singlet state and therefore the transition to the triplet state is forbidden (the non-zero transition probability is due to spin-orbit interaction mixing slightly the singlet and triplet states) therefore the radiative decay rate is small at low temperatures.

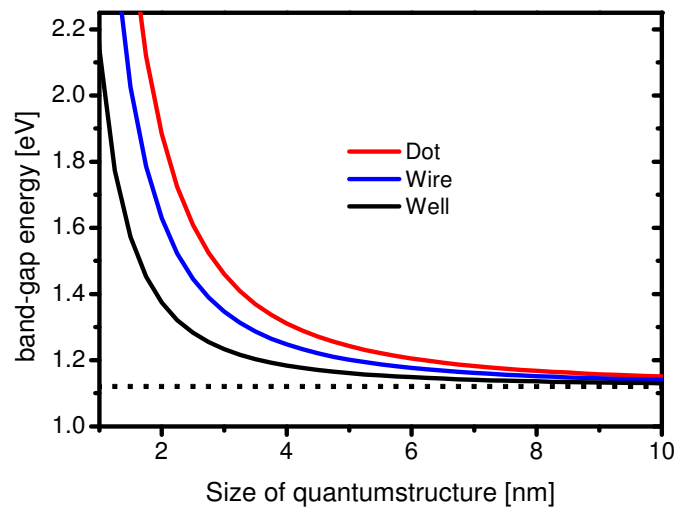

Fig. 6. Optical gap in Si quantum wells, wires, and dots, versus systems diameter. The transition energy is calculated for the lowest electron and heavy hole energies for infinite confining potentials after Ref (Lockwood et al., 1992).

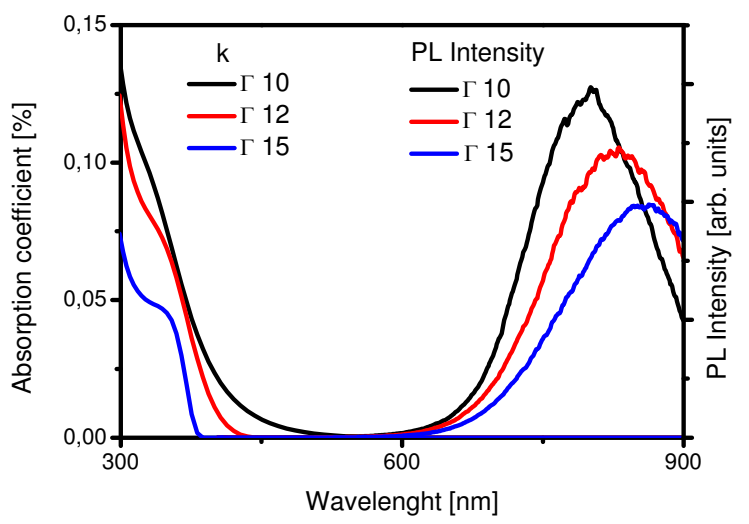

Fig. 7. Absorption coefficient and RT photoluminescence spectra of films containing Si-QDs obtained by thermal annealing of silicon rich oxide films (larger $\Gamma$ less silicon excess => smaller). 
At higher temperatures the singlet state becomes populated and the decay rate increases. The exciton splitting energy $\Delta$ increased for lower wavelength of PL (smaller Si-dots) and is in the range of 8 to $15 \mathrm{meV}$ and much larger than the $0.15 \mathrm{meV}$ of exchange splitting for the exciton observed in bulk silicon. The use of energy selective-optical spectroscopy allows to gain further inside in the behaviour of Si-QDs (Kovalev et al., 1998): Resonant PL-spectra obtained by exciting a subset of Si-QDs (selected by excitation at the low energy side of the broad PL emission band) show emission bands, which can be assigned to transitions involving either no momentum conserving phonons, or transitions involving the absorption or emission of one or two transversal acoustical or transversal optical phonons. Observation of the ratio of the intensity of zero-phonon to phonon assisted transitions indicate that although the transition probability is enhanced due to the quantum confinement effects, the bandgap of the Si-QDs remains indirect. Finally by measuring the PL spectra of single SiQDs at low temperature (down to $35 \mathrm{~K}$ ) emission line widths as low as $2 \mathrm{meV}$ were found. In addition dots with and without a Transverse Optical (TO) phonon replica were observed and the presence or absence of the phonon replica seems to depend on the degree of localisation of the exciton (Sychugov et al. 2005).

The description of properties of Si-QDs based on recombination of confined excitons explains a lot of the experiments performed, however not all the experimental findings can be exclusively explained within the model presented before: i) depending on the process of fabrication, the Si-QDs or quantum wells can be either crystalline or amorphous and the presence of both species makes the interpretation of experimental findings more complicated (Nesheva et al., 2002). ii) the photoluminescence properties observed can be influenced by defect states or photoluminescence active centres in the matrix or at the interface between the Si-QD and the matrix, iii) properties of Si-QDs are found to be strongly influenced by strain. Already from early studies on porous silicon it is well known that the intensity of photoluminescence depends on the quality of the surface of the nanocrystals and treatment with hydrogen at elevated temperatures was found to be very efficient in reducing the number of defects, which favour non-radiative recombination. In silicon nanocrystals embedded in $\mathrm{SiO}_{2}$ a series of defect centres, such as $\mathrm{O}$ vacancy, $\mathrm{O}$ thermal donors and $\mathrm{Si}$ dangling bonds, were identified using electron-spin resonance spectroscopy (Prokes et al., 1998). While dangling bonds act as non radiative recombination centers, which can be passivated with hydrogen (Garrido Fernandez et al., 2002; Godefroo et al., 2008), oxygen related defects are believed to play also a role in the radiative recombination process. The presence of these defects results in a photoluminescence band typically at higher emission energy than the band related to the exciton recombination and differs from the later one in decay time and temperature dependence (Tsybeskov et al., 1994; Kanemitsu 1994; Min et al., 1996; Kanemitsu et al. 1997). The oxygen related surface states are also believed to play an important role in the observation of stimulated emission from Si-QDs (Pavesi et al., 2000, Ruan et al., 2003, Dal Negro et al., 2003). Finally in a series of studies it is observed that the photoluminescence properties of silicon containing films depend also on film stress and on the stress at the interface between the Si-QD and the matrix (Khriachtchev et al., 2001; Daldosso et al., 2003; Zatryb et al., 2011).

\subsection{Electrical transport properties}

Interestingly early work on conduction processes and charging in Si-QDs embedded in a oxide matrix was performed back in 1984 by DiMaria (DiMaria et al. 1984a; DiMaria et al. 
1984b) some years before the observation of light emission from porous silicon initiated the boom of research in silicon photonics. DiMaria and coworkers studied the electrical and electro-optical properties of annealed silicon-rich-oxide containing Si-quantum dots, observed electroluminescence - for which they proposed carrier relaxation in quantum confined silicon as origin, and discussed the transport of carriers in the material. The conduction mechanism in dielectric matrices containing Si-QDs depends strongly on the type of matrix (silicon dioxide, silicon-nitride and silicon carbide are the most commons one) and on the distance between the Si-QDs. When Si-QDs are prepared by phase separation from silicon rich oxide two distinct regions can be found in conductivity measurements: a region in which the content of excess silicon is so large that the Si-QDs are not isolated anymore but form a percolation backbone and a lower Si-excess region in which the Si-QDs are isolated and conductivity is dominated by tunneling processes (Balberg et al., 2007). In the region of large Si-excess the conductivity is in the order of 10-7 $(\mathrm{Ohm} \mathrm{cm})^{-1}$, which is about 3 orders of magnitude lower than the conductivity of high resistivity floating zone silicon $\left(\sim 10^{-4}(\mathrm{Ohm} \mathrm{cm})^{-1}\right)$. For heavily boron doped films, conductivity values of about $0.1(\mathrm{Ohm} \mathrm{cm})^{-1}$ were reported by Mirabella et al. (Mirabella et al., 2010). However as shown in (Balberg et al., 2007) in this high Si-excess regime (above the percolation threshold) the photoluminescence observed for isolated Si-QDs is absent due to the growth of the cluster size and hence relaxation of the quantum confinement effect. For this reason this clustered structures seem less favorable for many of the illustrated application of Si-QDs reviewed here. Conductivity in $\mathrm{SiO}_{2}$ films with isolated Si-QDs is in the order of $10^{-10}(\mathrm{Ohm} \mathrm{cm})^{-1}$ (Balberg et al. 2007). In recent years films representing this type of structure were intensively investigated especially for realization of silicon base light emitting devices (Perálvarez et al., 2006; Franzò et al., 2002; Prezioso et al., 2008) and references therein. For the realization of light emitting diodes the oxide in a metal-oxide-semiconductor (MOS) structure is replaced by the Si-QDs containing material and the top electrode thickness reduced to obtain a semitransparent electrode. This diodes show under a forward bias, which strongly depends on the composition of the active material, electroluminescence in the spectral region around 730$830 \mathrm{~nm}(1.5-1.7 \mathrm{eV})$, characteristic for the emission from the Si-QDs. In LED's the Si-QD has to be excited by the carriers injected from the external circuit. Silicon dioxide has an energy gap of $\sim 9 \mathrm{eV}$ and the barrier heights are about $3.2 \mathrm{eV}$ and $4.7 \mathrm{eV}$ for electrons and holes respectively. Due to the difference in the barrier height it is in case of a $\mathrm{SiO}_{2}$ matrix much easier to inject electrons than holes. Direct tunneling of carriers through an oxide is the dominating conduction process only if the $\mathrm{SiO}_{2}$ thickness is smaller than $\sim 1.5 \mathrm{~nm}$. For larger distances transport is assumed to take place by Fowler Nordheim tunneling, in which the height of the barrier is reduced by the applied electric field and the electrons are accelerated. These hot electrons can then result in the formation of exciton-hole pairs by impact ionization of the nanocrystals, which then relax radiatively. The important information from these studies for use of Si-QDs in solar cells is twofold: 1st conductivity is rather low, $2^{\text {nd }}$ it is difficult to have a balanced situation regarding electron and hole current (at least if the embedding material is silicon dioxide). Several strategies are currently investigated to improve carrier transport in and from quantum confined Si-QDs: Very accurate placing of the Si-QDs controlling the distance between the dots within a range of $1.5 \mathrm{~nm}$ to $2 \mathrm{~nm}$ allows to obtain carrier injection by direct tunneling of both holes and electrons and in such structures electroluminescence was observed applying very low 
voltages (Anopchenko et al. 2009). A common route for fabrication of these multi-layer stacks with controlled Si-quantum dot distances is explained in section 3.3.1. An alternative route for improving the conductivity is to substitute silicon dioxide with other materials with smaller band-gap than silicon. Widely investigated matrices are $\mathrm{Si}_{3} \mathrm{~N}_{4}$ and $\mathrm{SiC}$ with bandgaps of 5.3 and $2.85 \mathrm{eV}$, respectively. The conduction band offset is $2.4 \mathrm{eV}$ for $\mathrm{Si}_{3} \mathrm{~N}_{4}$ and $2.95 \mathrm{eV}$ for $\mathrm{SiC}$. Indeed, recently for $\mathrm{Si}$ quantum dots in silicon nitride matrix conductivities between $10^{-4}(\mathrm{Ohm} \mathrm{cm})^{-1}$ and $10^{-2}(\mathrm{Ohm} \mathrm{cm})^{-1}$ are reported (Wan et al., 2011), which is a huge increase with respect to the conductivity values found for Si-QDs in $\mathrm{SiO}_{2}$. Finally, the conductivity of Si-QD containing materials can be increased by doping. SiQDs in silicon dioxide matrix are typically doped with either boron or phosphor to obtain p-type and n-type conducting films, which would allow to engineer $p-n$ junctions similar to the ones for standard silicon solar cells. For doping of Si-QDs large concentrations of dopants are needed. The typical dopant concentrations are around 1 atom\%. An increase of the conductivity of several orders of magnitude is reported for both boron and phosphor doping. Si-QDs can be doped with boron or phosophor, which seem to act as electron acceptor or donor similar as in bulk-silicon. Interestingly boron and phosphor doping has opposite effects on the photoluminescence efficiency (Hao et al., 2009). While in phosphor doped films the photoluminescence intensity increases in doped films, it decreases for boron doped films. Current studies indicate that phosphor doping reduces the number of dangling bonds - acting as as non-radiative recombination centers - at the quantum-dot $/ \mathrm{SiO}_{2}$ interface (Stegner et al., 2008), while boron doping results in contrary in an increase of non-radiative recombination centers (Zatryb et al., 2010).

\section{Si-quantum dots in solar cells}

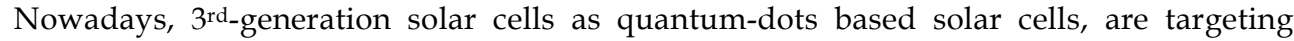
significant increases in energy conversion efficiency. With the perspective of using the energy confinement of silicon based quantum dot nanostructures, different concepts of solar cells can be found in the literature. Through these concepts, four promising approaches can be retained: (i) Down-conversion and down-shifting solar cells (Klampaftis et al., 2009; Richards, 2006a): In this case, the aim is to make a more efficient utilization of the short wavelength part of the solar spectrum, mainly by producing more than one low-energy photons from the absorption of one high-energy photon (for which the cell quantum efficiency (QE) is low), or by shifting high energy photons to a lower energy photon for which the cell QE is high. (ii) Hot carrier solar cells (Luque \& Marti, 2010, Nozik et al., 2010): in this scheme, solar-to-electricity energy conversion is enhanced by reducing energy losses related to the absorption of solar photons with energy larger than the bandgap of the active photovoltaic material. (iii) All-silicon tandem or multijunction solar cells (Conibeer et al., 2008; Di et al., 2010): here, the expected increase in efficiency is due to a multi-band gap approach. The cell with the highest band gap is placed on the very top, while the cell with the lowest band gap is positioned at the bottom of the tandem stack. Each cell absorbs the light it can most effectively convert, with the rest passing through to the underlying cells. (iv) Inorganic/organic solar cells (Buhbut et al., 2010): the principle scopes of the use of QDs in this approach are twofold: $1^{\text {st }}$ the light harvesting can be improved by broadening the region in which light is absorped through the use of QDs of different size, $2^{\text {nd }}$ the lifetime of the cell is improved by replacing organic molecules with more stable inorganic ones. 


\subsection{Si-QDs as spectral converters for solar cells}

Aim of spectral converters is the more efficient utilization of the short-wavelength $(\lambda)$ part of the solar spectrum. Under a spectral converter we understand a material or film, which by absorption and re-emission changes the spectral distribution and numbers of photons of the solar spectrum impinging on the converting layer. Two distinct physical mechanisms are explored in this context: down-conversion and down-shifting. In down conversion one photon with energy $h v \geq 2 E_{g}$. yields 2 photons (in the ideal case) with energies $h v \geq E_{g}$. Down-conversion improves the performance of solar cells by minimizing the thermalisation losses in solar cells. The maximum efficiency improvement for a solar cell with a bandgap of $1.1 \mathrm{eV}$ (crystalline silicon) was estimated to be $38.6 \%$ placing the spectral converter on top of the solar cell (Trupke et al., 2002). Down-conversion is mainly observed for rare-earth ion doped materials and occurs either on single ions or involves energy transfer processes among different rare earth ions. A description of rare-earth based down converting phosphors is found in (Richards B.S., 2006b). For Si-QDs up to now no down-conversion process is reported. However for Si-QDs the generation of multiple excitons (MEG) was reported, which is somehow similar to down-conversion since it results in the formation of more than 1 exciton of low energy from a high energy exciton. MEG in the context of Si-QDs will be discussed in section 3.2. In down-shifting a high energy photon is absorbed by the spectral converter and re-emitted at lower energy. The process of down-shifting in silicon QDs accompanied with a radiative energy transfer from the QDs to the solar cell is depicted in Figure 8. The absorption of incident high energy photons and re-emission at lower energy can be achieved with every three level systems. A first and fast non radiative relaxiation takes place between the highest excited level and the intermediate level. In this case the emission of only one lower energy photon is accompanied by the radiative

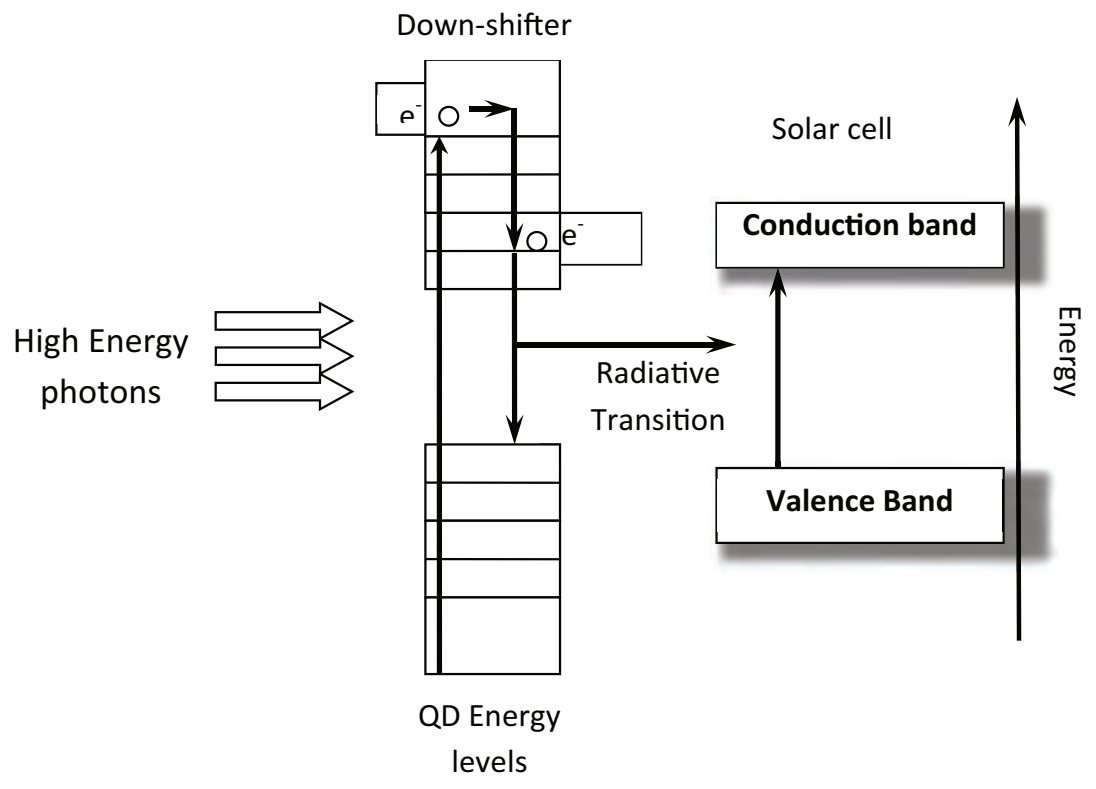

Fig. 8. Schematic energy diagram of a solar cell in combination with a spectral down-shifter. 
recombination of the electron from the intermediate level to the lowest level. As a result of the luminescent process, a part of the incident photons are shifted to longer wavelength before reaching the active photovoltaic material of the device. Aim of the down-shifting process is to maximize the number of incoming photons in the spectral region in which the internal quantum efficiency (IQE) of the solar cell is at its maximum. In solar cells based on crystalline silicon the IQE is lower for photons with wavelengths shorter than $\sim 450 \mathrm{~nm}$ (due to recombination of carriers generated close to the surface -surface recombination) and very high between $\sim 500$ and $1000 \mathrm{~nm}$. For this reason a downshifting of UV-blue photons to the red-NIR region can result in a larger short circuit current and hence an improvement of the External Quantum Efficiency of the device. The two others electrical characteristics of the device i.e. the open-circuit voltage and the fill factor will not change significantly, since the electronic properties of the semiconducting material or the resistance of the device remain unchanged.

A typical schematic representation of a photovoltaic spectral converter is illustrated in Figure 9. It is constituted of four separate layers. In this case Silicon QDs i.e. the active material are located on the front surface of the device and the layer is electronically isolated from the solar cell by an insulator layer, i.e. the coupling between the active medium and the solar cell is purely radiative. A perfect mirror is located on the rear surface of the device to provide high internal surface reflectance for all angles of incidence of light. In order to be used as downconverter for all type of existing solar cells, Silicon QDs has to respect the following trend: (i) the absorption band has to be large enough to cover the region where the External Quantum Efficiency of the cell is low (UV-blue region in Silicon based solar cells); (ii) the absorption coefficient has to be as high as possible; (iii) the emission band has to cover a spectral band where the external quantum efficiency of the cell is the best (i.e. red region in Silicon based solar cells); (iv) the energy difference between the absorption band and emission band i.e. the difference between the conduction and valence band has to be large enough to avoid reabsorption phenomenon of the emitted photons. One of the main advantage of using quantum dots in general, and it is also true for Silicon QDs, as down-shifters in solar cells is that both light absorption and emission can be tuned by choice of the dot diameter. Furthermore Si-QDs have a large quantum efficiency (over $50 \%$, Walters, R.J. 2006), which is another important requisite to obtain an enhancement in efficiency of the solar cell (see below). Preliminary simulation results made on ideal QDs by van Sark have demonstrated the great capacity of QDs as down-shifting species (van Sark et al., 2004). Indeed calculation have shown that quantum dots with an emission at $\sim 600 \mathrm{~nm}$ increase the multicrystalline solar cell short-circuit current by nearly $10 \%$. The simulation shows that the most beneficial effects will be accomplished if the spectral response of solar cells has a specific form such that the spectral response is low at low wavelengths and high at high wavelengths. When considering the critical parameters that influence the performance of down-conversion solar cells, we may pin down three essential factors: one is the energy distribution of the incident spectra the second is the presence or not of an anti reflecting coating on the front face of the solar cell and the third is the surface recombination. Jestin et al (Jestin et al., 2010) have shown on a c-Si solar cell, that the effect of a down-conversion layer containing Silicon QDs on the Power Conversion Efficiency (PCE) is rather low.

Simulation and experimental results have confirmed that an increase in the cell performance can be observed only in case of poor performance of the cell in the UV-blue region (e.g. very high surface recombination velocity). In this case solar cells with a luminescent downconversion layer can outperform normal c-Si based solar cells. The first experimental tests with 
silicon QDs as a down-converter were performed by Svreck et al (Svreck et al., 2004) and described the embedding of Silicon QDs into spin-on-glass antireflecting $\mathrm{SiO}_{2}$ based solution spun onto standard silicon solar cells. In this case the interest is to take advantage of the emission properties of the Silicon QDs that can be tuned by their size, as a result of quantum confinement (Alivisatos, 1996). The interest of quantum dots with respect to other downconverting species like organic dyes molecules (McIntosh \& Richards, 2006; Maruyama et al., 2000; Richards \& McIntosh, 2007) or rare-earth ion complexes (Ledonne et al., 2009, Ledonne et al., 2010) are their high brightness, stability and quantum efficiency (Bruchez et al., 1998). One main advantage of the application of a luminescent down-conversion layer on solar cells lies in the fact that the luminescence down-converter is only optically coupled to the solar cell and in principle spectral down converter and solar cell can be optimized independently. This down-conversion concept mainly shifts the photons from the blue to the red.

Incident Light

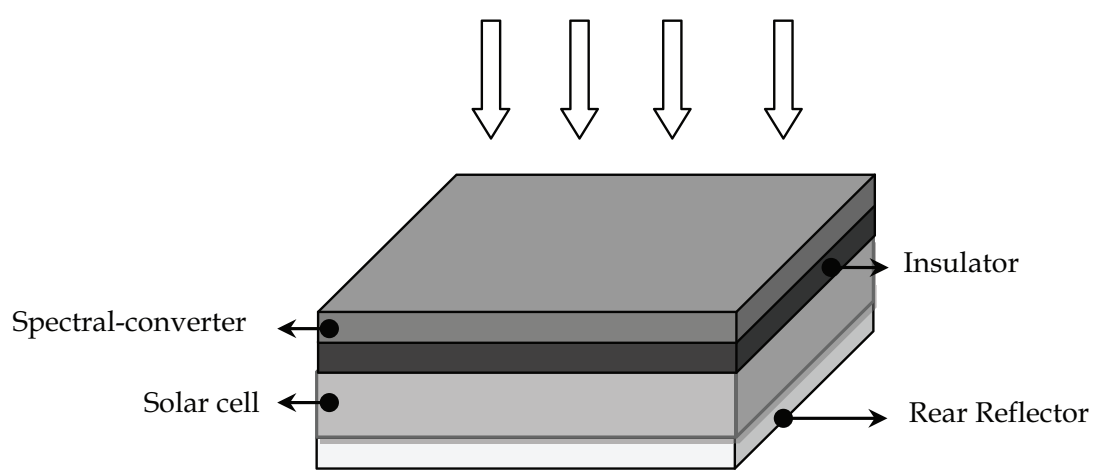

Fig. 9. Schematic representation of a photovoltaic down-converter based device.

Recent years saw several studies on the Si QD based downs-shifters: (most important results are summarized in Table 1):

\begin{tabular}{|c|c|c|c|c|c|}
\hline $\begin{array}{l}\text { Solar } \\
\text { cell }\end{array}$ & $\begin{array}{l}\text { Quantum } \\
\text { dots }\end{array}$ & $\begin{array}{c}\text { Host } \\
\text { material }\end{array}$ & $\begin{array}{c}\text { Performance } \\
\text { difference } \\
{[\%]}\end{array}$ & $\begin{array}{l}\text { Illuminating } \\
\text { spectrum }\end{array}$ & Reference \\
\hline a-Si & Ideal QDs & Ideal plastic & $\begin{array}{c}\text { No } \\
\text { improvement }\end{array}$ & AM1.5G & $\begin{array}{l}\text { [Sark et al., } \\
\text { 2004] }\end{array}$ \\
\hline c-Si & Silicon QDs & $\mathrm{SiO}_{2}$ & $\begin{array}{c}\text { No } \\
\text { improvement }\end{array}$ & AM1.5G & $\begin{array}{l}\text { [Jestin et al., } \\
\text { 2010] }\end{array}$ \\
\hline c-Si & Silicon QDs & $\begin{array}{l}\text { Spin-on } \\
\text { Glass }\end{array}$ & +0.4 & AM1.5 & $\begin{array}{l}\text { [Svrcek et al., } \\
\text { 2004] }\end{array}$ \\
\hline c-Si & Silicon QDs & $\begin{array}{l}\text { Organic } \\
\text { solvent }\end{array}$ & +0.6 & - & [Pi et al., 2011] \\
\hline Poly-Si & Silicon QDs & $\begin{array}{l}\text { Directly on } \\
\text { cell }\end{array}$ & +10 & Visible light & $\begin{array}{l}\text { [Stupca et al. } \\
\text { 2007] }\end{array}$ \\
\hline
\end{tabular}

Table 1. Performance results of Silicon QDs based luminescent down-shifters 
Svrcek et al observe an efficiency increase of about $0.4 \%$. In this case the Silicon QDs were prepared ex-situ (pulverizing of electrochemical etched porous silicon) embedded into a spin-on-glass anti-reflecting $\mathrm{SiO}_{2}$ based solution and then onto a standard silicon solar cell. They claim that an improvement of the Internal Quantum Efficiency (IQE) has been detected in the region 300-500 $\mathrm{nm}$. The difference observed in the solar cell performance points out the difficulty to compare the efficiency of silicon QDs in different conditions. Indeed $\mathrm{Pi}$ et al. who report an increase in efficiency of $0.6 \%$ claim that the efficiency improvement observed by Svreck et al may have been due to the improved optical coupling of the light into the cell by Silicon QDs embedded in the spin-on glass at the solar cell surface (Pi et al., 2011). The authors claim that it is the porous nature of the deposited film which could be at the origin of the observed efficiency increase (porous silicon layers are well known as anti-reflecting coating (Chaoui et al., 2008)) rather than a down-conversion effect of silicon QDs. In their paper, Pi et al propose to deposit a silicon QDs based ink at the solar cell surface by spin-coating. Silicon QDs are produced using a new synthesis approach (Mangolini et al., 2005) and dispersed in an organic solvent. In this case, an enhancement of $2.3 \%$ in short circuit current (Isc) is observed, and thus consistent with the fact that the Silicon QDs film induce an enhancement of light absorption and then an increase in the cell efficiency. Finally Stupca et al. (Stupca et al., 2007), deposited Si-QDs dispersed in a volatile solvent directly on a industrial polycrystalline solar cell. The Si-QDs used showed depending on size either strong blue (1nm diameter) or orange/red $(2.85 \mathrm{~nm})$ photoluminescence. A huge improvement of up to $70 \%$ was reported shining blue light on the cells (in this spectral region the IQE of the cell is poor) and an still notable efficiency improvement of $10 \%$ was obtained for visible light. Current results on Si-QDs as down shifters allow to envision that improvements of some percents in efficiency can be expected from this approach within the next years.

\subsection{Hot carrier solar cells and multiple exciton generation in Silicon QDs}

Here we address two concept which try to avoid the losses due to thermalisation of hot carriers. One is the so called hot carrier solar cells (HCSC), which aims on the extraction of hot carrier before they relax to the bandedges, the other is based on the generation of multiple excitons (MEG) from high energy excitons observed in a series of QDs.

Hot carrier solar cells (HCSC) presented in Figure 10 have been proposed in early 80' as a promising approach to increase the efficiency of conventional solar cells (Ross \& Nozik, 1982 ; Takeda et al., 2009; Würfel et al., 2005). The thermalisation of photoexcited involving lattice phonons reduces significantly the number of carriers which can be effectively separated through the $\mathrm{p}$-n junction, thus, preventing to achieve high voltages in a photovoltaic cell. A possibility to reduce the thermalisation time, which is known to be the main loss mechanism in photovoltaic cells, would allow collecting more carriers when these are still excited to higher energetic states (hot carriers) and therefore increase the cell voltage. Generally speaking, in bulk semiconductor-based solar cells, the damping of the thermalisation rate is achieved at very high intensities (order of 1000 suns, see for example Ref. (Würfel, 1997)). On the other hand, in low dimensional nanostructures, such as 1D superlatticies, the larger (artificial) translation period with respect to the lattice period of an ordinary crystal results in a much smaller Brillouin zone and, as a consequence, in very small number of acoustic phonon modes, preventing fast thermalisation of excited carriers (an enhancement of the phonon bottleneck effect) (Nozik 
et al., 1990; Westland et al., 1988). In the last years 0D systems, quantum dots and semiconductor nanocrystals, have attracted much interest. As already discussed above, these material systems have the advantage to improve the efficiency of the absorbing layer of the photovoltaic cell. In case of HCSC, a quantum dot system can have an important role also in realizing energy selective contacts (Conibeer et al., 2006; Conibeer et al., 2008). The basic concept standing behind this idea consists in increasing the efficiency of an HCSC device by collecting the photogenerated in the absorbing layer hot carriers over a very small energy range with selective energy contacts (SEC). In Ref. (Conibeer et al., 2006) Conibeer and co-workers introduce the quantum dot approach for SEC where a double-barrier resonant tunnelling structure is described (here a QD-based layer with a discrete energy level is embedded between two insulating layers). An electrode with such a configuration should result in strongly peaked conduction at a discrete energy level (Figure 10).
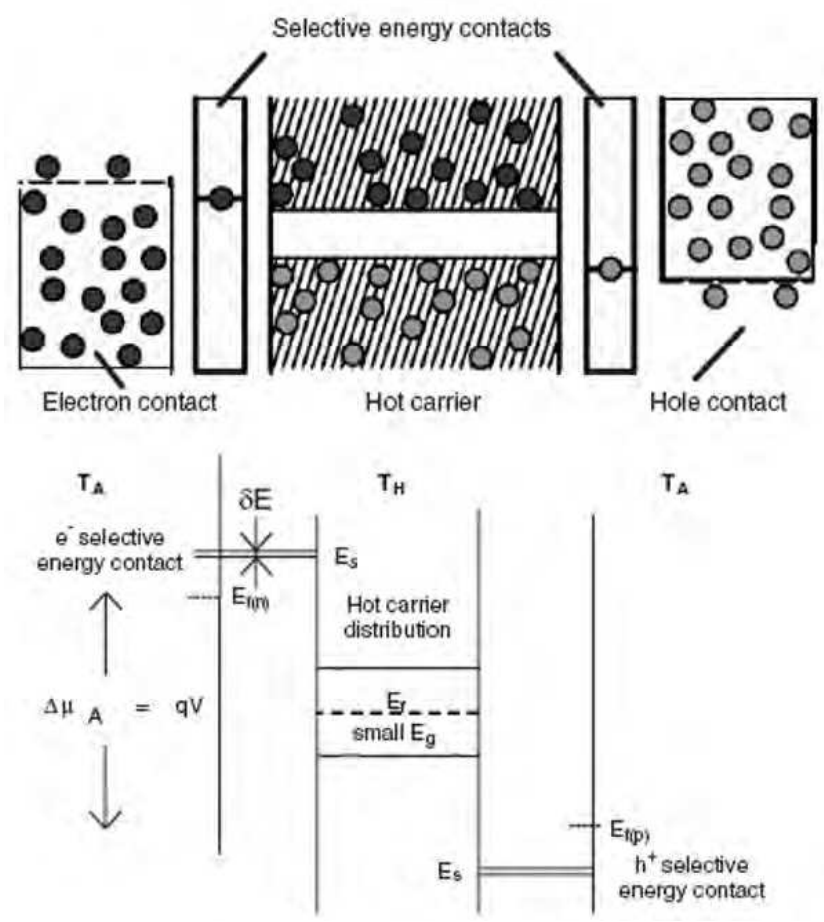

Fig. 10. The schematic of a hot carrier solar cell with energy selective electrodes. Reprinted from Thin Solid Films, Vol.511-512, Conibeer, G. et al., Films Silicon nanostructures for third generation photovoltaic solar cells, pp. 654-662, Copyright (2006), with permission from Elsevier. (Conibeer et al., 2006).

Proof-of-concept experiments have been realized by using silicon nanocrystals (Si-ncs) embedded in a silica matrix as double-barrier electrodes (Conibeer et al., 2008). The double barrier resonant tunneling structure used in this work comprises in a $4 \mathrm{~nm}$ thick Si-nc layer sandwiched between two $5 \mathrm{~nm} \mathrm{SiO} 2$ barrier layers. Si-ncs have been formed through a high 
temperature treatment of the multilayer structure, which is known to result in a phase separation of $\mathrm{Si}$ and $\mathrm{SiO}_{2}$ inside the silicon rich silica layer. The layer thickness controls the size of the Si-ncs which in its turn is providing the specific discrete energy levels inside the double tunnelling barrier. The significant result in this study is the observation of room temperature negative differential resistance (NDR) feature in the I-V curve of the electrode (Figure 11). Despite the weak NDR resonance observed in these experiments, the results, as an evidence for 1D energy selection, are very encouraging. Recently, HCSC devices with Sinc-based energy selective electrodes have been studied in much detail addressing the growth, compositional, structural and spectroscopic properties of the nanocrystalline system (Aliberti et al., 2010; Shrestha et al., 2010).
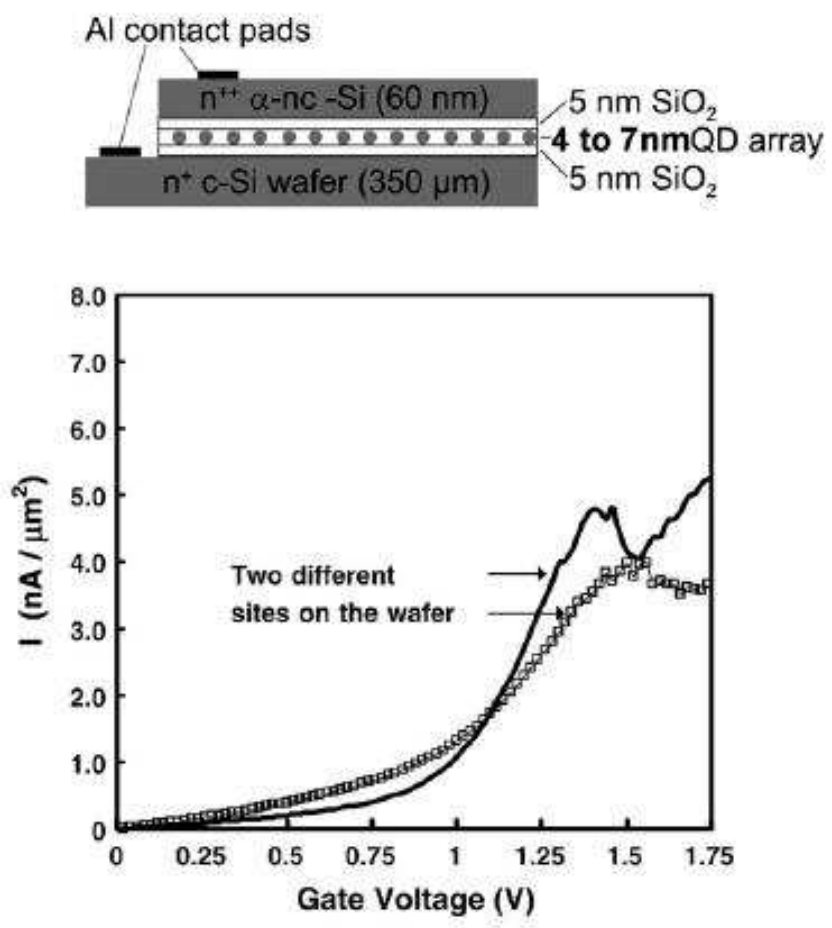

Fig. 11. (top) The sketch of SEC experiments and I-V curves at room temperature showing the NDR features. Reprinted from Thin Solid Films, Vol. 516, No.20, Conibeer, G. et al., Selective energy contacts for hot carrier solar cells, pp. 6968-6973, Copyright (2008), with permission from elsevier. (Conibeer et al., 2008).

The concept of using Si-nc-based energy selective electrodes proved to offer an important potential to improve the efficiency of HCSC photovoltaic cells, however, further work on significantly improved the NDR resonance quality and characteristics is expected in the next years.

Multiple exciton generation has been investigated and demonstrated by Beard et al in different types of semiconductor QDs (PbS, PbSe, PbTe, CdS, CdSe, InAs, and Si) (Beard et 
al., 2007). In a conventional photovoltaic semiconductor device, the absorption of a photon usually results in the production of a single electron-hole pair; energy of a photon in excess of the semiconductor's bandgap is efficiently converted to heat through electron and hole interactions with the crystal lattice. Recently, colloidal semiconductor QDs and QDs-based films have been shown to exhibit efficient multiple electron-hole pair generation from a single photon with energy greater than twice the effective band gap. This multiple carrier pair process, referred to as multiple exciton generation (MEG), represents one route to reducing the thermal loss in semiconductor solar cells. In the case of Silicon QDs, Beard et al. investigated carrier multiplication using femtosecond transient absorption sectroscopy to study three different sizes of colloidal Si-QDs suspended in a nonpolar solvent (Beard et al., 2007). The authors found that MEG occurs with considerably higher efficiency in Si-QDs as compared to bulk $\mathrm{Si}$, showing a threshold in $9.5 \mathrm{~nm}$ diameter QDs (effective band gap $\mathrm{Eg}=1.20 \mathrm{eV}$ ) to be $2.4 \pm 0.1 \mathrm{Eg}$, and this same size QD showed an exciton quantum yield of $2.6 \pm 0.2$ excitons per absorbed photon at $3.4 \mathrm{Eg}$. The measurements were the first reported occurrence of MEG in an indirect-gap semiconductor. The authors also investigated larger QDs and found that even for relatively small confinement energy of $80 \mathrm{meV}$, high photon energies produced efficient MEG. To this point for usefull photovoltaics applications involving Si-QDs, the QDs must be coupled electronically to their environment. Solar energy applications attempting to harness the MEG-created electron-hole pairs there are several requirements that any approach must justify; (i) The QDs must be the active component, (ii) efficient transport of electrons and holes, or excitons, must occur over macroscopic distances and (iii) the coupling can not be so strong as to reduce the MEG efficiency yet must be strong enough to separate the electron-hole pairs either by undergoing charge transfer or diffusing one exciton to a nearby QD that does not have an exciton prior to non-radiative Auger recombination. Interestingly, the indirect nature of the silicon bandgap, which is preserved in Si-QDs, and which is detrimental to photonic applications, turns out to be beneficial here, as the relatively long exciton lifetime (in comparison with direct-badgap QDs) simplifies energy extraction for photovoltaic applications.

\subsection{Multilayer tandem solar cells}

Tandem solar cells are meant to absorb a major part of the solar spectrum and hence to increase the efficiency of the device by increasing the electric current. The approach is to fabricate $\mathrm{p}-\mathrm{n}, \mathrm{p}-\mathrm{i}-\mathrm{n}$ or any other diode structure with different band gap semiconductors and connect them to enhance the photovoltaic conversion. The fundamental limit of the performance of tandem structures has been studied by Meillaud et al (Meillaud et al., 2006). The radiative efficiency limit for a single junction silicon cell is 30\%. This increases to $42.5 \%$ and $47.5 \%$ for 2-cell and 3-cell tandem stacks respectively. For an AM1.5G solar spectrum the optimal band gap of the top cell required to maximize conversion efficiency is $\sim 1.7$ to $1.8 \mathrm{eV}$ for a 2-cell tandem with a Si bottom cell and $1.5 \mathrm{eV}$ and $2.0 \mathrm{eV}$ for the middle and upper cells for a 3- cell tandem. As shown in Figure 12, the first cell located at the front is fabricated with a wide band-gap material to convert high-energy photons from the blue-end whereas the third cell located at the back is fabricated with a narrow band-gap material to convert low-energy photons from the infra-red end. With this approach, the next step is to connect the cells together to form one device. Two types of connection can be envisioned: in series or in parallel. In series, devices are connected using a tunnel junction, and the n-type 
material of one device is connected to the p-type material of the adjacent device i.e. conduction band and valence band are connected to each others. In parallel, the material changes its conduction gradually from $n$ to $\mathrm{p}$.

With the aim of fabricating an "all-Si" tandem solar cell for third generation photovoltaics, silicon QDs in combination of an inexpensive silicon thin-film technology may allow the fabrication of higher band gap solar cells. Taking the advantage of quantum confinement effects in silicon, a band gap engineering can be achieved by optimizing the silicon QDs size. Indeed when silicon is made very thin (in the order of a few nanometers) in one or more dimensions, quantum confinement causes its effective band gap to increase. The strongest effect is obtained when silicon is confined in 3D (i.e., quantum dots). If the quantum dots are close to each other, carriers can tunnel between them to form quantum dot superlattices, which can be used as the higher band gap cells in a tandem stack.

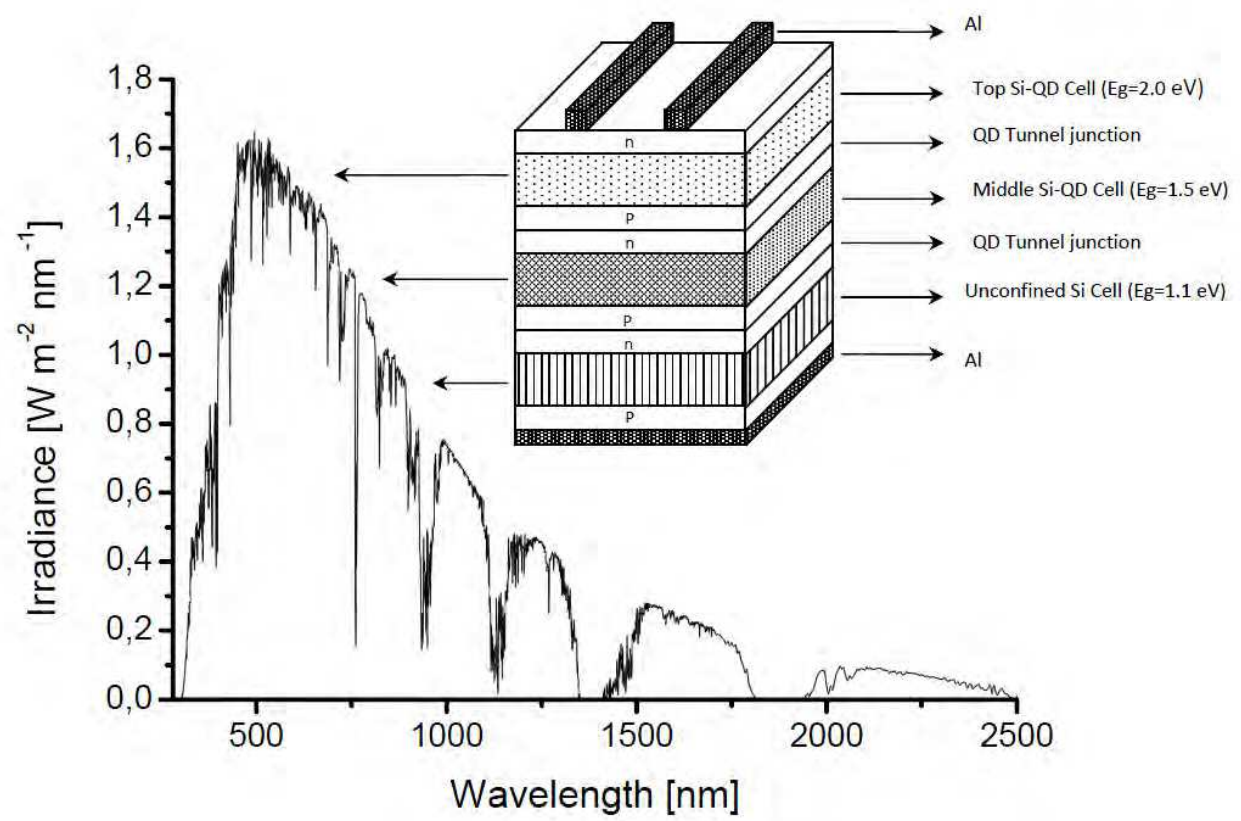

Fig. 12. Solar AM1.5G spectrum and arrangement of three different p-n junctions to utilize photons in the three regions. The cell materials have larger band gap in the cell located in the top than the cell located on the bottom.

\subsubsection{Engineering of the silicon QDs stack}

In order to obtain crystalline QDs of controlled size and distance, which allows also electrical carrier transport, layer thickness has to be controlled on nanometer scale. Quantum confined nanostructures of silicon with barriers of $\mathrm{SiO}_{2}, \mathrm{Si}_{3} \mathrm{~N}_{4}$ or $\mathrm{SiC}$ can potentially fulfil these criteria. Hence common thin film techniques deposition like PECVD are used to fabricate silicon QDs stacks. This multilayer deposition typically 
consist of the repetition of a tens of bi-layers of silicon rich dielectric and stochiometric dielectric. The deposition is followed by annealing in $\mathrm{N}_{2}$ from 1050 to $1150^{\circ} \mathrm{C}$ inducing the precipitation of silicon nanocrystals or QDs. The process is depicted in Figure 13 together with TEM images of superlattices and silicon QDs. Similarly to a traditional p-n junction, a QD p-n junction is required to separate the photon-generated electron-hole pairs. This junction may be achieved by doping the silicon QDs with impurity atoms to form a nanoscale p-n junction. From a fabrication point of view, the introduction of a few impurity atoms into a QD that contains only a few hundred atoms may lead to their expulsion to the surface or compromise the crystal structure. This will inherently create a heavily doped QD under strong quantum confinement.

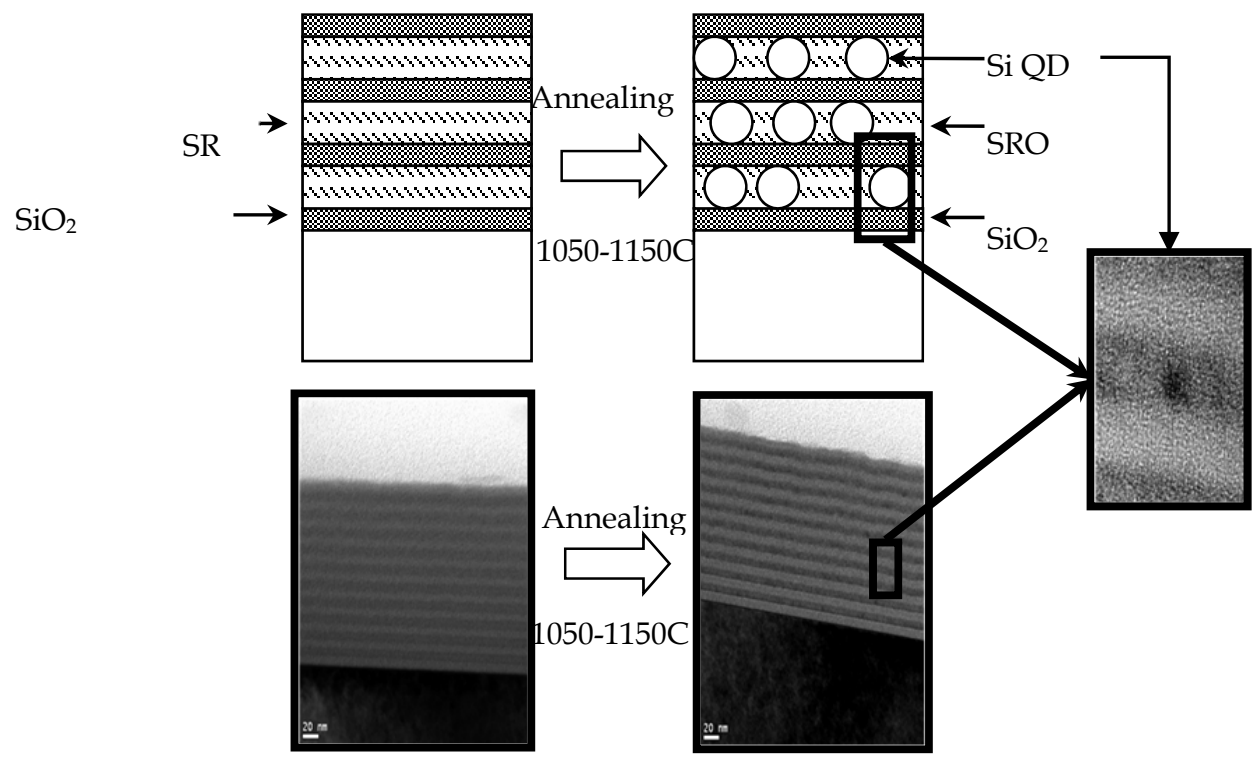

Fig. 13. Multilayer structure illustrating precipitation of silicon QDs in a Si-rich layer.

The electronic and optical properties in such circumstances are still unresolved. Thus, QDs doping still remains a critical step for tailoring their properties for specific applications in solar cells. To this date, no realization of an all silicon tandem cell has been done, nevertheless, important research in this field has lead to the development of a method to dope semiconductor nanocrystals with metal impurities, enabling control of the band gap and Fermi energy. In this case, a combination of optical measurements, scanning tunneling spectroscopy, and theory revealed the emergence of a confined impurity band and bandtailing (Mocata et al., 2011). This method yields n- and p-doped semiconductor nanocrystals, which have potential applications in all silicon tandem solar cells. In Table 2 recent results obtained on silicon solar cells with QDs as active material are summarized. 


\begin{tabular}{|c|c|c|c|c|c|}
\hline $\begin{array}{c}\text { Solar cell } \\
\text { configuration }\end{array}$ & Voc [mV] & $\mathrm{Jsc}\left[\mathrm{mA} / \mathrm{cm}^{2}\right]$ & FF [\%] & $\begin{array}{c}\text { Efficiency } \\
{[\%]}\end{array}$ & \\
\hline $\begin{array}{l}\text { Doped Si-QD } \\
\text { p-i-n } \\
\text { homojunction } \\
\text { diodes on quartz }\end{array}$ & $\begin{array}{c}\left.493 \text { (Si-QD:SiO }{ }_{2}\right) \\
83 \text { (Si-QD:SiC) }\end{array}$ & $\begin{array}{c}0.003 \mathrm{~mA} \\
\left(\mathrm{SiQd}: \mathrm{SiO}_{2}\right)^{*}\end{array}$ & $\begin{array}{c}\text { Not } \\
\text { determined }\end{array}$ & $\begin{array}{c}\text { Not } \\
\text { determined }\end{array}$ & [Lima, 2011] \\
\hline $\begin{array}{l}\text { Doped Si- } \\
\text { QD:SiO } \\
\text { (n- or p-type) } \\
\text { heterojunction }\end{array}$ & $\begin{array}{l}556(\mathrm{n}) \\
613(\mathrm{p})\end{array}$ & $\begin{array}{l}29.8(\mathrm{n}) \\
32.0(\mathrm{p})\end{array}$ & $\begin{array}{l}67.1(\mathrm{n}) \\
73.1(\mathrm{p})\end{array}$ & $\begin{array}{l}11.1(\mathrm{n}) \\
14.3(\mathrm{p})\end{array}$ & [Lima, 2011] \\
\hline $\begin{array}{l}\text { Doped Si- } \\
\text { QD:SiC (p-type) } \\
\text { heterojunction } \\
\text { on c-Si }\end{array}$ & 463 & 19.0 & 53.0 & 4.66 & $\begin{array}{l}\text { [Song et al., } \\
\text { 2008] }\end{array}$ \\
\hline $\begin{array}{l}\text { Doped Si-QD } \\
\text { (p-type) } \\
\text { heterojunction } \\
\text { on c-Si }\end{array}$ & 540 & 28 & 66 & 9.5 & $\begin{array}{l}\text { [Hong et al., } \\
\text { 2010] }\end{array}$ \\
\hline $\begin{array}{l}\text { Undoped Si-QD } \\
\text { on quartz with } \\
\text { poly-Si } \\
\text { electrodes }\end{array}$ & $\begin{array}{c}220 \\
\left(\mathrm{Si}-\mathrm{QW}: \mathrm{SiO}_{2}\right) \\
286 \\
\left(\mathrm{Si}-\mathrm{QD}: \mathrm{Si}_{3} \mathrm{~N}_{4}\right)\end{array}$ & $\begin{array}{c}0.6\left(\mathrm{Si}^{-}\right. \\
\left.\mathrm{QW}: \mathrm{SiO}_{2}\right) \\
0.0012\left(\mathrm{Si}^{-}\right. \\
\left.\mathrm{QD}: \mathrm{Si}_{3} \mathrm{~N}_{4}\right)\end{array}$ & $\begin{array}{c}30\left(\mathrm{Si}^{-}\right. \\
\left.\mathrm{QW}: \mathrm{SiO}_{2}\right)\end{array}$ & $\begin{array}{c}0.041 \\
\left(\mathrm{Si}-\mathrm{QW}: \mathrm{SiO}_{2}\right)\end{array}$ & [Lima, 2011] \\
\hline $\begin{array}{l}\text { Undoped } \\
\text { Si-QD:SiON } \\
\text { heterojunction } \\
\text { diodes on c-Si }\end{array}$ & 485 & 12.5 & 11.4 & 0.69 & $\begin{array}{l}\text { [Prezioso } \\
\text { et al., 2009] }\end{array}$ \\
\hline
\end{tabular}

Table 2. Recent results obtained on silicon solar cells with Si-QDs as active material *I not J as area is too small to define

\subsection{Inorganic/organic solar cells}

First reports on silicon/organic hetero-junctions date back to 1982 (Forrest et al., 1982). At this time, devices were based on small organic molecules evaporated on crystalline silicon wafers. The use of such hetero-junctions for photovoltaic applications has been first reported with pyrene as the organic compound (Mccaffrey \& Prasad, 1984), thus opening the road to silicon/organic based solar cells. One can distinguish two type of organic solar cells: (i) the organic bulk hetero-junction (OBHJ) solar cell (Park et al., 2009) based on a hole conductor and an electron acceptor material. The mixture poly(3-hexylthiophene): 1-(3methoxycarbonyl)propyl-1-phenyl[6,6]C61 (P3HT:PCBM) is currently the most prominent material system in organic photovoltaic, (ii) the dye sensitized solar cell (DSSC) (ORegan \& Grätzel, 1991), based on a semiconductor formed between a photo-sensitized anode and an electrolyte. The introduction of silicon QDs in such devices finds its interest in increasing the electro-optical properties of the cell and thus increasing the external quantum efficiency of the device. In order to understand the behavior of silicon QDs with conducting polymer, Dietmueller et al (Dietmueller et al., 2009) have reported the charge transfer between silicon QDs and the component of a bulk hetero-junction solar cells (P3HT and PCBM). In figure 14 the conduction band (CB) and the valence band (VB) of silicon as well as the lowest 
unoccupied molecular orbital (LUMO) and the highest occupied molecular orbital HOMO of P3HT are displayed based on literature values.

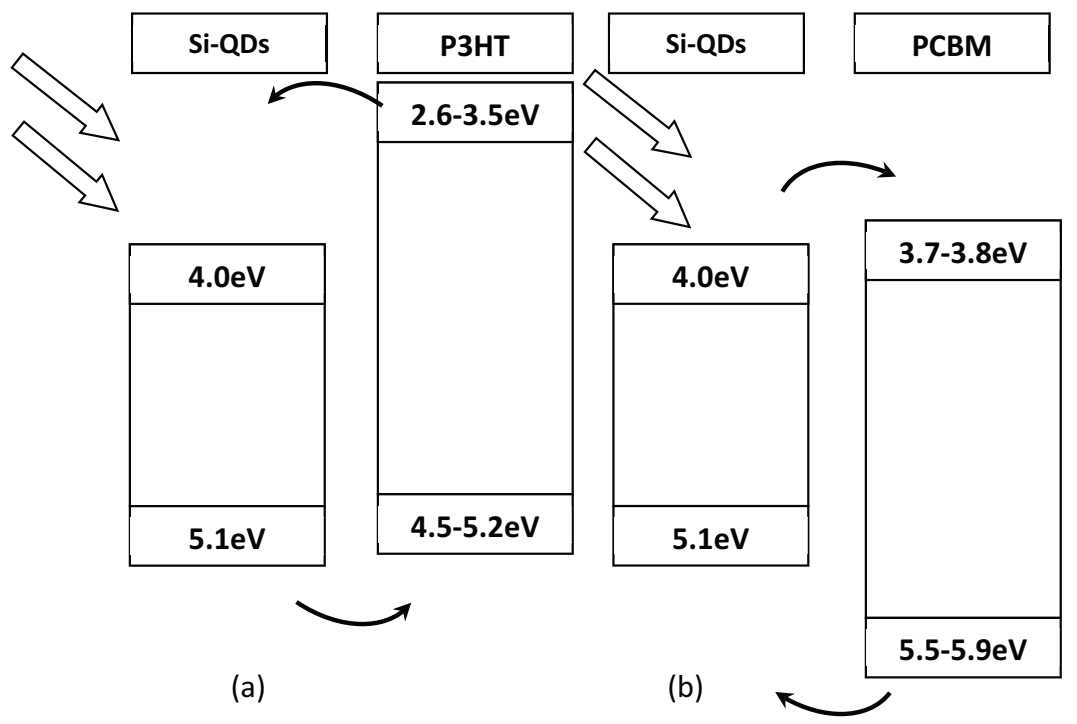

Fig. 14. Schematic view of the energy levels of Silicon-QDs and P3HT (a) and of Si-nc and PCBM (b). The curved arrows indicate the transfer direction of electrons and holes.

The LUMO of P3HT lies clearly above the CB of Si (Figure 14 a), enabling dissociation of excitons followed by an electron transfer to the Si CB. However, taking into account the different literature values of the HOMO of P3HT (4.7-5.2 eV) (Al-Ibrahim et al., 2005) and possible influences on the band alignment, such as Fermi level pinning or interface dipoles, it is a priori not clear if a hole transfer from the Si VB to the P3HT HOMO can take place. For the photogeneration of the positive polarons of $\mathrm{P} 3 \mathrm{HT}(\mathrm{P}+)$ in the Sinc/P3HT system, one can consider different scenarios: After the light induced generation of excitons in P3HT, the excitons dissociate by electron transfer to Silicon QDs, while the holes remain in the P3HT. Alternatively, an energy transfer might occur, whereby excitons are transferred from P3HT to the Silicon QDs, followed by a back transfer of the holes (Gowrishankar et al., 2006). A third possibility is that, after light absorption in the Silicon, the holes are transferred from the Silicon QDs to the P3HT. In any case, for all the processes it is required that the HOMO of P3HT lies energetically above the Si-QDs VB. As we indeed do detect light induced $\mathrm{P}+$ in the P3HT, we can conclude that this requirement is fulfilled, which is a prerequisite for solar cells based on P3HT and Si-QDs. The analogous argument holds for the alignment of the LUMO (3.7-3.8 eV) (Al-Ibrahim et al., 2005) of PCBM and the CB of Silicon QDs (Figure 14 b) where we detect PCBM- anions in the Silicon QDs/PCBM composite during illumination. Thus the LUMO of PCBM must be energetically lower than the Silicon QDs CB. Despite the fact that PCBM, in contrast to $\mathrm{P} 3 \mathrm{HT}$, is not a good absorber for the solar spectrum, the Silicon QDs/PCBM material combination could in principle be used for solar cell applications as well. 

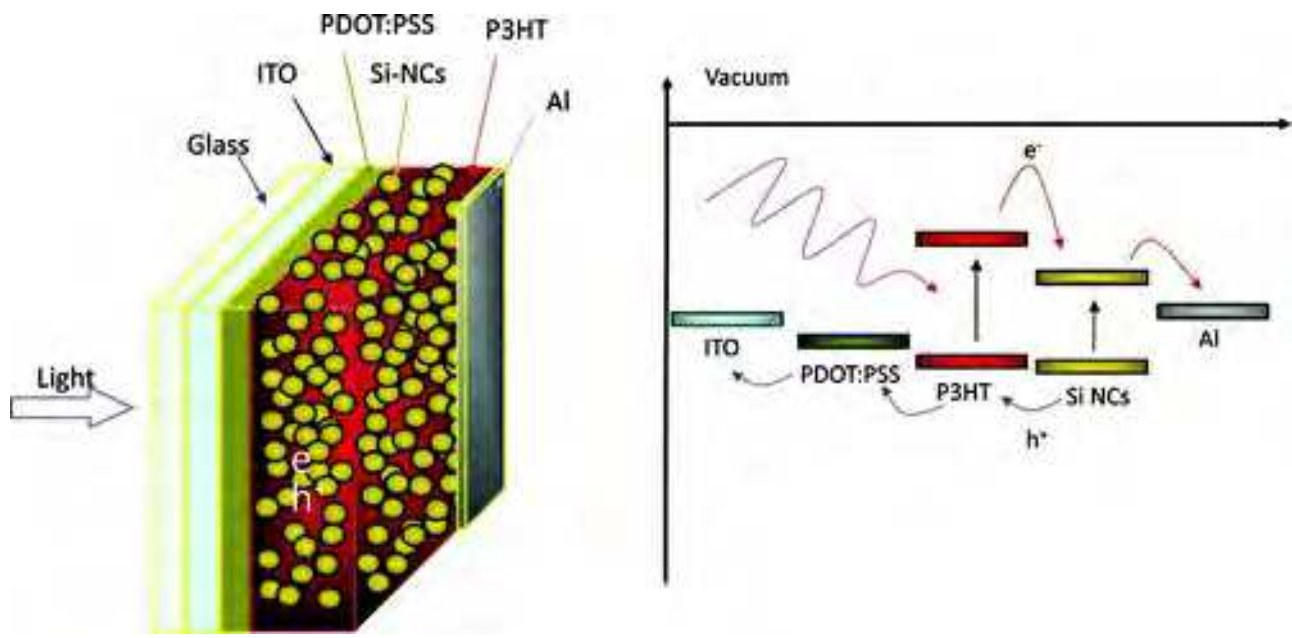

Fig. 15. Cell configuration and Energy level diagram of the nc-Si/P3HT solar cell. Reprinted with permission from (Liu et al., Nano Letters, Vol.9, No.1, (2009), pp. 449-452. Copyright (2009) American Chemical Society (Liu et al., 2009).

\subsubsection{Performance of Silicon QDs in organic solar cells}

Experimental data on the system silicon QDs/P3HT have been reported by Liu et al (Liu et al., 2009). They reported new hybrid solar cells based on blends of Silicon QDs and P3HT polymer in which a percolating network of the nanocrystals acts as the electron-conducting phase. A schematic representation of the organic bulk hetero-junction solar cell with all the energy level is depicted in Figure 15. The authors found that the open-circuit voltage and short-circuit current are observed to depend on the Silicon QDs size due to changes in the bandgap and surface-area-to-volume ratio. Under simulated one-sun A.M. 1.5D direct illumination $\left(100 \mathrm{~mW} / \mathrm{cm}^{2}\right)$, devices made with $35 \mathrm{wt} \%$ with silicon QDs of 3-5 $\mathrm{nm}$ in size showed $1.15 \%$ power conversion efficiency.

\begin{tabular}{cccl}
\hline Organic phase & Performance [\%] & Illuminating spectrum & \multicolumn{1}{c}{ Reference } \\
\hline P3HT & 1.15 & AM1.5D & [Liu et al., 2009] \\
MDMO-PPV & 0.49 & AM1.5D & {$[$ Liu, 2009] } \\
C $_{60}$ & $\begin{array}{c}1.4 \text { (under } \\
400 \mathrm{~nm})\end{array}$ & - & [Svreck et al., 2010] \\
\hline
\end{tabular}

Table 3. performances of Silicon QDs Hybrid cells.

Using the same solar cell configuration, Liu reported also some experiments on a cell consisting of 3-5 nm silicon QDs and poly [2-methoxy-5-(3',7'-dimethyloctyloxy)-1,4phenylenevinylene] (MDMO-PPV) and fabricated from solution processes. The hybrid cells of 58wt $\%$ 3-5 nm Si NCs/MDMO-PPV showed a power conversion efficiency of $0.49 \%$ under simulated one sun A.M. 1.5D direct illumination $(100 \mathrm{~mW} / \mathrm{cm} 2)$ (Liu, 2009). In comparison with the previous results based on $\mathrm{P} 3 \mathrm{HT}$ cells, the low efficiency of the Silicon 
QDs/MDMO-PPV may result from the lower hole mobility and narrow absorption spectrum of MDMO-PPV. The energy band alignment of Silicon QDs and MDMO-PPV may also be one of the factors limiting device efficiency. Using a different approach, Svreck et al (Svrcek et al., 2010) reported experimental data on Silicon QD/Fullerene $\left(\mathrm{C}_{60}\right)$ solar cells. They first demonstrate that Silicon QDs can be electronically coupled with fullerenes $\left(\mathrm{C}_{60}\right)$ without any additional surfactant or catalyst. The fabrication of an Hetero-junction solar cells made out of Silicon QDs and $\mathrm{C}_{60}$ show photovoltaic action with increased quantum efficiency in the region where the absorption of Silicon QDs appears. The cell shows and External Quantum Efficiency (EQE) over $1.4 \%$ at high energies ( $\geq 400 \mathrm{~nm}$ ) and a power conversion efficiency up to $0.06 \%$ in the spectral region $550-700 \mathrm{~nm}$. In Table 3 are resumed the performances of Si-QDs Hybrid cells reported in the literature.

\section{Conclusions}

In this review we presented recent results on the application and research on Si-QDs related to photovoltaics. This research is strongly related to future demands in electricity generation. Fascinating scientific results were shown in the field of hot-carrier cells and multi-exciton generation. It is far too early to understand if these phenomena and concepts will play an important role from a technological point of view, but deep scientific investigation of the underlaying processes will be necessary. However simpler concepts like down-shifting are on the way of being applyied on existing solar technology. In addition a series of studies on QDs in heterojunction solar cells showed cell efficiencies in the range of $5-10 \%$. It is important to note that Si-QDs can also play a role in organic based solar cells development. Even if this research is still in an initial phase, encouraging results have been demonstrated. Although all these cells are still far away from outperforming best c-Si cells they are in an efficiency range which justifies deep investigation. A critical issue will be to achieve similar and even larger effiencies on QD solar cells which are not based on a crystalline silicon substrate.

\section{Acknowledgment}

Authors acknowledge financial support throught the European Commison by the project LIMA (Improve Photovoltaic efficiency by applying novel effects at the limis of light to matter interaction (FP7-ICT-2009.3.8-248909)).

\section{References}

Aliberti, P.; Shrestha, S.K.; Teuscher, R.; Zhang, B.; Green, M.A. \& Conibeer, G.J. Study of silicon quantum dots in a $\mathrm{SiO} 2$ matrix for energy selective contacts applications. Solar Energy Materials and Solar Cells, Vol.94, No.11, (November 2010), pp. 19361941, ISSN 0927-0248.

Alivisatos, A.P. Perspectives on the Physical Chemistry of Semiconductor Nanocrystals. Journal of Physical Chemistry, Vol.100, No.31, (August 1996), pp. 13226-13239, ISSN 0047-2689.

Al-Ibrahim, M.; Roth, H.-K.; Schroedner, M.; Konkin, A.; Zhokhavets, A.; Gobsch, G.; Scharff, P. \& Sensfuss, S. The influence of the optoelectronic properties of poly(3- 
alkylthiophenes) on the device parameters in flexible polymer solar cells. Organic Electronics, Vol.6, No.2, (April 2005), pp. 65-77, ISSN 1566-1199.

Amato, G.; Delerue, C. \& VonBardeleben, H.J. (1997). Structural and optical properties of porous silicon nanostructures, (Optoelectronic properties of semiconductors and superlattices) Gordon and Breach Science Publishers, ISBN 90-5699-604-5, Amsterdam.

Anopchenko, A.; Marconi, A.; Moser, E.; Prezioso, S.; Wang, M.; Pavesi, L.; Pucker, G. \& Bellutti, P. Low-voltage onset of electroluminescence in nanocrystalline-Si/SiO2 multilayers. Journal of applied physics, Vol.106, No.3, (August 2009), pp. 033104033112, ISSN 1089-7550.

I. Balberg, E. Savir, J. Jedrzejewski, A. G. Nassiopoulou and S. Gardelis. Fundamental transport processes in ensembles of silicon quantum dots. Physical review B, Vol.75, No.23, (June 2007), pp. 235329-235337, ISSN 1550-235X.

Becquerel, E. (1867) La lumière, ses causes, ses effets, tome II, Firmin diderot frères, ISBN 88-1163036-3, Paris.

Bisi, O.; Osscini, S. \& Pavesi, L. Porous silicon: a quantum sponge structure for silicon based optoelectronics. Surface Science Reports, Vol.38, No.1-3, (April 2000), pp. 1-126, ISSN 0167-5729.

Brabec, C.; Dyakonov, V. \& Scherf, U. (2008). Organic Photovoltaics - Materials, Devices, and Manufacturing Technologies, Wiley-VCH Verlag Gmbh \& Co. KGaA, ISBN 978-3-52731675-5, Weinheim, Germany.

Brongersma, M. L.; Kik, P.G.; Polman, A.; Min, K.S. \& Atwater, H.A. Size-dependent electron hole exchange interaction in Si nanocrystals. Applied Physics Letters, Vol. 76, No.3, (January 2000), pp. 351-1-351-3, ISSN 1077-3118.

Bruchez, M.; Moronne, M.; Gin, P.; Weiss, S. \& Alivisatos, A.P. Semiconductor Nanocrystals as Fluorescent Biological Labels. Science, Vol.281, No. 5385, (September 1998), pp. 2013-2016, ISSN 1095-9203.

Buhbut, S.; Itzhakov, S.; Tauber, E.; Shalom, M.; Hod, I.; Geiger, T.; Garini, Y.; Oron, D. \& Zaban, A. Built-in Quantum Dot Antennas in Dye-Sensitized Solar Cells. ACS Nano, Vol.4, No.3, (March 2010), pp. 1293-1298, ISSN 1936-086X.

Calcott, P.D.J.; Nash, K.J.; Canham, L.T.; Kane, M.J. \& Brumhead, D. Identification of radiative transitions in highly porous silicon. Journal of physics: Condensed Matter, Vol.5, No.7, (February 1993), pp.91-98, ISSN 1361-648X.

Canham, L.T. Silicon quantum wire array fabrication by electrochemical and chemical dissolution of wafers. Applied Physics Letters, Vol.57, No.10, (September 1990), pp. 1046-1-1046-3, ISSN 0003-6951.

Canham, L.T (2007). Properties of porous silicon, (Leigh Canham), Institution of Engineering and Technology, ISBN 0863415555, 9780863415555), London.

Chaoui, R.; Mahmoudi, B. \& Si Ahmed, Y. Porous silicon antireflection layer for solar cells using metal-assisted chemical etching. Physica Status Solidi A, Vol.205, No.7, pp. 1724-1728, (July 2008), ISSN 1862-6319.

Chapin, D.M.; Fuller, C.S. \& Pearson, G.S. A new silicon p-n junction photocell for converting solar radiation into electrical power. Journal of Applied Physics, Vol.25, No.5, (May 1954), pp. 676- ISSN 1089-7550. 
Chelikowsky, J.R. \& Cohen, M.L. Nonlocal pseudopotential calculations for the electronic structure of eleven diamond and zinc-blende semiconductors. Physical Review B, Vol.14, No.2, (July 1976) pp. 556-582, ISSN 1550-235X.

Conibeer, G.; Jiang, C.W.; König, D.; Shrestha, S.; Walsh, T. \& Green, M.A. Selective energy contacts for hot carrier solar cells. Thin Solid Films, Vol.516, No.20, (August 2008), pp. 6968-6973, ISSN 0040-6090.

Conibeer, G.; Green, M.A.; Corkish, R.; Cho, Y.; Cho, E.C.; Jiang, C.W.; Fangsuwannarak, T.; Pink, E.; Huang, Y.; Puzzer, T.; Trupke, T.; Richards, B.S.; Shalav, A. \& Lin, K.L. Silicon nanostructures for third generation photovoltaic solar cells. Thin Solid Films, Vol.511-512, (July 2006), pp. 654-662, ISSN 0040-6090.

Conibeer, G.; Green, M.A.; Cho, E.C.; König, D.; Cho, Y.H.; Fangsuwannarak, T.; Scardera, G.; Pink, E.; Huang, Y.; Puzzer, T.; Huang, S.; Song, D.; Flynn, C.; Park, S.; Hao, X. \& Mansfield, D. Silicon quantum dot nanostructures for tandem photovoltaic cells. Thin Solid Films, Vol.516, No.20, pp. 6748-6756, (August 2008), ISSN 0040-6090.

Cullis, A.C. \& Canham, L.T. Visible light emission due to quantum size effects in highly porous crystalline silicon. Nature, Vol.353, No.6342, (September 1991), pp. 335-338, ISSN 1476-4687.

Cullis, A.C., Canham, L.T. \& Calcott, J.P.D. The structural and luminescence properties of porous silicon. Applied Physics Reviews, Vol.82, No.3, (August 1997), pp. 909-965, ISSN 0021-8979.

Daldosso, N.; Luppi, M.; Ossicini, S.; Degoli, E.; Magri, R.; Dalba, G.; Fornasini, P.; Grisenti, R.; Rocca, F.; Pavesi, L.; Boninelli, S.; Priolo, F.; Spinella, C. \& Iacona, F. Role of the interface region on the optoelectronic properties of silicon nanocrystals embedded in $\mathrm{SiO}_{2}$. Physical Review B, Vol.68, No.8, (August 2003), pp. 085327-085335, ISSN 1550-235X.

Dal Negro, L.; Cazzanelli, M.; Pavesi, L.; Ossicini, S.; Pacifici, D.; Franzò, G.; Priolo, F. \& Iacona, F. Dynamics of stimulated emission in silicon nanocrystals. Applied Physics Letters, Vol.82, No.26, (June 2003), pp. 4636-4639, ISSN 1077-3118.

Del Cañizo, C.; Del Coso, G. \& Sinke, W.C. Crystalline silicon solar module technology: Towards the $1 €$ per watt-peak goal. Progress in Photovoltaics: Research and Applications, Vol.17, No.3, (May 2009), pp. 199-209, ISSN 1099-159X.

Di, D.; Perez-Wurfl, I.; Conibeer, G. \& Green, M.A. Formation and photoluminescence of Si quantum dots in $\mathrm{SiO} 2 / \mathrm{Si} 3 \mathrm{~N} 4$ hybrid matrix for all-Si tandem solar cells. Solar Energy Materials and Solar Cells, Vol.94, No.12, (December 2010), pp. 2238-2243, ISSN 0927-0248.

Dietmueller, R.; Stegner, A.R.; Lechner, R.; Niesar, S.; Pereira, R.N.; Brandt, M.S.; Ebbers, A.; Trocha, M.; Wiggers, H. \& Stutzmann, M. Light-induced charge transfer in hybrid composites of organic semiconductors and silicon nanocrystals. Applied Physics. Letters. Vol.94, No.11, (March 2009), pp. 113301, ISSN 1077-3118.

DiMaria, D.J.; Dong, D.W.; Pesavento, F.L.; Lam, C. \& Brorson, S. D. Enhanced conduction andminimized charge trapping in electrically alterable read-only memories using off stoichiometric silicon dioxide films. Journal of Applied Physics, Vol.55, No.8, (April 1984), pp. 3000-3020, ISSN 1089-7550.

DiMaria, D.J.; Kirtley, J.R.; Pakulis, E.J.; Dong, D.W.; Kuan, T.S.; Pesavento, F.L.; Theis, T.N.; Cutro, J.A. \& Brorson, S.D. Electroluminescence studies in silicon dioxide films 
containing tiny silicon islands. Journal of Applied Physics, Vol.56, No.2, (July 1984), pp. 401-417, ISSN 1089-7550.

Dovrat, M.; Goshen, Y.; Jedrzejewski, J.; Balberg, I. \& Sa'ar, A. Radiative versus nonradiative decay processes in silicon nanocrystals probed by time resolved photoluminescence spectroscopy. Physical Review B, Vol.69, No.15, (April 2004), pp. 155311-155319, 1550-235X.

European Photovoltaic Technology Platform. (2007). A strategic research agenda for photovoltaic solar energy technology, ISBN 978-92-79-05523-2, date of access: 10/08/11, Available from: www.eupvplatform.org.

Feltrin, A. \& Freundlich, A. Material considerations for terawatt level deployment of photovoltaics. Renewable Energy, Vol.33, No.2, (February 2008), pp. 180-185, ISSN 0960-1481.

Feng, J.C. \& Tsu, R. (1994). Porous silicon (Tsu, R.), World Scientific, ISBN 981-02-1634-3, Singapore.

Forrest, S. R.; Kaplan, M. L.; Schmidt, P. H.; Feldmann, W. L. \& Yanowski, E. Organic-oninorganic semiconductor contact barrier devices. Applied Physics Letters, Vol.41, No.1, (July 1982), pp. 90-93, ISSN 0003-6951.

Franzò, G.; Irrera, A.; Moreira, E.C.; Miritello, M.; Iacona, F.; Sanfilippo, D.; Di Stefano, G.; Fallica, P.G. \& Priolo, F. Electroluminescence of silicon nanocrystals in MOS structures. Applied Physics A, Vol.74, No.1, (January 2002) pp. 1-5, ISSN 1432-0630.

Garrido Fernandez, B.; Lopez, M.; García, C.; Pérez-Rodríguez, A.; Morante, J.R.; Bonafos, C.; Carrada, M. \& Claverie, A. Influence of average size and interface passivation on the spectral emission of $\mathrm{Si}$ nanocrystals embedded in $\mathrm{SiO}_{2}$. Journal of Applied Physics, Vol.91, No.2, (January 2002), pp. 798-808, ISSN 1089-7550.

Godefroo, S.; Hayne, M.; Jivanescu, M.; Stesmans, A.; Zacharias, M.; Lebedev, O.I.; Van Tendeloo, G. \& Moshchalkov, V.V. Classification and control of the origin of photoluminescence from Si nanocrystals. Nature Nanotechnology, Vol.3, No.3 (March 2008), pp. 174-178, ISSN 1748-3387.

Gowrishankar, V; Scully, S. R.; McGehee, M.D.; Wang, Q. \& Branz, H. M. Exciton Splitting and Carrier Transport across the Amorphous-Silicon/Polymer Solar Cell Interface. Applied Physics Letters, Vol.89, No.25, (December 2006), pp. 252102, ISSN 1077-3118.

Green, M.A.; Emery, K.; Hishikawa, Y. \& Warta, W. Solar cell efficiency tables (version 36). Progress in Photovoltaics: Research and Applications, Vol.18, No.5, (August 2010), pp. 346-352, ISSN 1099-159X.

Hao, X.J.; Cho, E.C.; Scardera, G.; Shen, Y.S.; Bellet-Amalric, E.; Bellet, D.; Conibeer, G. \& Green, M.A. Phosphorus-doped silicon quantum dots for all-silicon quantum dot tandem solar cells. Solar Energy Materials and Solar Cells, Vol.93, No.9, (September 2009), pp. 1524-1530, ISSN 0927-0248.

Hirshman, W.P.; Hering, G. \& Schmela, M. Gigawatts-the measure of things to come. Photon International, Vol.3, No.12, (March 2007), pp. 136-166.

Hong, S.H.; Park, J.H.; Shin, D.H.; Kim, C.O.; Choi, S.H. Doping and size dependent photovoltaic properties of p-type Si-Quantum dot heterojunction solar cell: correlation with photoluminescence. Applied Physics Letters, Vol.97, No.7, (August 2010), pp. 072108-1-072108-3, ISSN 
Jestin, Y.; Pucker, G.; Ghulinyan, M.; Ferrario, L.; Bellutti, P.; Picciotto, A.; Collini, A.; Marconi, A.; Anopchenko, A.; Yuan, Z. \& Pavesi, L. Silicon solar cells with nanocrystalline silicon down shifter: experiment and modeling. Proceeding SPIE optics and photonics, pp. 77721-77727, ISBN 9780819483119, San Diego, USA, August 2-5, 2010.

Kanemitsu, Y. Luminescence properties of nanometer-sized Si crystallites: Core and surface states. Physical Review B, Vol.49, No.23, (June 1994), pp. 16845-16848, ISSN 1550$235 X$.

Kanemitsu, Y.; Okamoto, S.; Otobe M. \& Oda, S. Photoluminescence mechanism in surfaceoxidized silicon nanocrystals. Physical review B, Vol.55, No.12, (March 1997), pp. R7375-R7378, ISSN 1550-235X.

Kelzenberg, M.D.; Boettcher, S.W.; Petykiewicz, J.A.; Turner-Evans, D.B.; Putnam, M.C.; Warren, E.L.; Spurgeon, J.M.; Briggs, R.M.; Lewis, N.S.; Atwater, H.A. Enhanced absorption and carrier collection in Si wire arrays for photovoltaic applications. Nature Materials, Vol.9. No.3, (March 2010), pp. 239-244, ISSN 1476-1122.

Khriachtchev, L.; Kilpelä, O.; Karirinne, S.; Keränen, J. \& Lepistö, T. substrate-dependent crystallization and enhancement of visible photoluminescence in thermal annealing of $\mathrm{Si} / \mathrm{SiO}_{2}$ superlattices. Applied Physics Letters, Vol.78, No.3, (January 2001), pp. 323-326, ISSN 1077-3118.

Klampaftis, E.; Ross, D.; McIntosh, K.R. \& Richards, B.S. Enhancing the performance of solar cells via luminescent down-shifting of the incident spectrum: A review. Solar Energy Materials and Solar Cells, Vol.93, No.8, (August 2009), pp. 345-351, ISSN 0927-0248.

Kovalev, D.; Heckler, H.; Ben-Chorin, M.; Polisski, G.; Schwartzkopff, M. \& Koch, F. Breakdown of the k-conservation rule in Si nanocrystals. Physical Review letters, Vol.81, No.13, (September 1998), pp. 2803-2806, ISSN 1079-7114.

Le Donne, A.; Acciarri, M.; Narducci, D.; Marchionna, S. \& Binetti, S. Encapsulating Eu3+ complex doped layers to improve Si-based solar cell efficiency. Progress in Photovoltaics, Vol.17, No.8, (December 2009), pp. 519-525, ISSN 1099-159X.

Le Donne, A.; Dilda, M.; Crippa, M.; Acciarri, M. \& Binetti, S. Rare earth organic complexes as down-shifters to improve Si-based solar cell efficiency. Optical Materials, Vol.33, No.7, (May 2011), pp. 1012-1014, ISSN 0925-3467.

Lehmann, V. \& Gosele, U. Porous silicon formation: A quantum wire effect. Applied Physics Letters, Vol. 58, No.8 (February 1991), pp. 856-1-856-3, ISSN 0003-6951.

Lima, European project Improve Photovoltaic efficiency by applying novel effects at the limis of light to matter interaction (FP7-ICT-2009.3.8-248909) internal report 2011.

Linnros, J.; Lalic, N.; Galeckas, A. \& Grivckas, V. Analysis of the stretched exponential photoluminescence decay from nanometer-sized silicon nanocrystals. Journal of Applied Physics, Vol.86, No.11, (December 1999), pp. 6128-6136, ISSN 1089-7550.

Liu, C.Y; Holman, Z.C. \& Kortshagen, U.R. Hybrid Solar Cells from P3HT and Silicon Nanocrystals. Nano Letters, Vol.9, No.1, (January 2009), pp. 449-452, ISSN 15306992.

Liu, C.Y. Hybrid Solar Cells from Polymers and Silicon Nanocrystals. PhD Tesis, University of Minnesota, (December 2009). 
Lockwood, D.J.; Aers, G. C.; Allard, L. B.; Bryskiewicz, B.; Charbonneau, S.; Houghton, D.C.; McCaffrey, J. P. \& Wang, A. Optical properties of porous silicon. Canadian Journal of Physics, Vol.70, No.10-11, (November 1992), pp. 1184- 1193, ISSN 1208-6045.

Lockwood, D.J.; Lu, Z.H. \& Baribeau, J.-M. Quantum Confined Luminescence in Si/SiO2 Superlattices. Physical Review letters, Vol.76, No.3, (March 1996), pp. 539-541, ISSN 1079-7114.

Luque, A. \& Marti, A. Electron-phonon Energy transfer in hot-carrier solar cells. Solar Energy Materials and Solar Cells, Vol.94, No.2, (February 2010), pp. 287-296, ISSN 0927-0248.

Mangolini, L.; Thimsen, E. \& Kortshagen, U. High-yield plasma synthesis of luminescent silicon nanocrystals. Nano Letters, Vol.5, No.4, (April 2005), pp. 655-659, ISSN ISSN 1530-6992.

Marketbuzz®. (March 2011). Shine a light on the global PV supply/demand market balance, In: The leading annual world solar PV Industry Report, date of access: 07/09/11, Available from: http:/ / www.solarbuzz.com.

Maruyama, T.; Enomoto, A. \& Shirasawa, K. Solar cell module colored with fluorescent plate, Solar Energy Materials and Solar Cells, Vol.64, No.3 , (October 2000), pp. 269278, ISSN 0927-0248.

McCaffrey, R.R. \& Prasad, P.N. Organic-thin-film-coated solar cells: Energy transfer between surface pyrene molecules and the silicon semiconductor substrate. Solar Cells, Vol.11, No.4, (May 1984), pp. 401-409, ISSN 0927-0248.

McIntosh, K.R. \& Richards, B.S. Increased mc-Si module efficiency using fluorescent organic dyes: a ray-tracing study, Proceedings of IEEE 4th World Conference on Photovoltaic Energy Conversion, pp. 2108-2111, ISBN 1-4244-0016-3, Waikoloa, Hawaii, USA, May 7-12, 2006.

Meillaud, F.; Shah, A.; Droz, C.; Vallat-Sauvarin, E. \& Miazza, C. Efficiency limits for singlejunction and tandem solar cells. Solar Energy Materials and Solar Cells. Vol.90, No.1819, (November 2006), pp. 2952-2959, ISSN 0927-0248

Min, K.S.; Shcheglov, K.V.; Yang, C.M.; Atwater, H.A.; Brongersma, M.L. \& Polman, A. Defect-related versus excitonic visible light emission from ion beam synthesized $\mathrm{Si}$ nanocrystals in $\mathrm{SiO}_{2}$. Applied Physics Letters, Vol.69, No.14, (September 1996), pp. 2033-1-2033-3, ISSN 1077-3118.

Mirabella, S.; Di Martino, G.; Crupi, I.; Gibilisco, S.; Miritello, M.; Lo Savio, R.; Di Stefano, M. A.; Di Marco, S.; Simone, F. \& Priolo, F. Light absorption and electrical transport in Si:O alloys for photovoltaics. Journal of Applied Physics, Vol.108, No.9, (November 2010), pp. 093507-093514, ISSN 1089-7550.

Mocatta, D.; Cohen, G.; Schattner, J.; Millo, O.; Rabani, E. \& Banin, U. Heavily Doped Semiconductor Nanocrystal Quantum Dots. Science, Vol. 323, No.4, (April 2011), pp 77-81, ISSN 1095-9203.

Nesheva, D.; Raptis, C.; Perakis, A.; Bineva, I.; Aneva, Z.; Levi, Z.; Alexandrova, S.; Hofmeister, H. Raman scattering and photoluminescence from Si nanoparticles in annealed $\mathrm{SiO}_{x}$ thin films. Journal of Applied Physics, Vol.92, No.8, (October 2002), pp. 4678-4683, ISSN 1089-7550.

Nozik, A.J.; Beard, M.C.; Luther, J.M.; Law, M.; Ellingson, R.J. \& Johnson, J.C. Semiconductor Quantum Dots and Quantum Dot Arrays and Applications of 
Multiple Exciton Generation to Third-Generation Photovoltaic Solar Cells. Chemical Review, Vol.110, No.11, (November 2010), pp. 6873-6890, ISSN 1520-6890.

O'Regan, B. \& Grätzel, M. A low-cost, high-efficiency solar cell based on dye-sensitized colloidal TiO2 films. Nature, Vol.353, No.6346, (October 1991), pp. 737-740, ISSN 1476-4687.

Park, S.H.; Roy, A.; Beaupre, S.; Cho, S.; Coates, N.; Moon, J.S.; Moses, D.; Leclerc, M.; Lee, K. \& Heeger, A.J. Bulk heterojunction solar cells with internal quantum efficiency approaching 100\%. Nature Photonics, Vol.3, No.5, (May 2009), pp. 297-303, ISSN $1749-4885$.

Pavesi, L.; Dal Negro, L.; Mazzoleni, C.; Franzò, G. \& Priolo, F. Optical Gain in Silicon Nanocrystals. Nature, Vol.408, No.6811, (November 2000), pp. 440-444, ISSN 00280836.

Perálvarez, M.; García, C.; López, M.; Garrido, B.; Barreto, J.; Domínguez, C. \& Rodríguez, J.A. Field effect luminescence from Si nanocrystals obtained by plasma-enhanced chemical vapor deposition. Applied physics Letters, Vol.89, No.5, (July 2006), pp. 051112-051115, ISSN 1077-3118.

Pi, X.; Li, Q.; Li, D. \& Yang, D. Spin-coating silicon-quantum-dot ink to improve solar cell efficiency. Solar Energy Materials and Solar Cells, Vol.95, No.10, (October 2011), pp. 2941-2945, ISSN 0927-0248.

Prezioso, S.; Anopchenko, A.; Gaburro, Z.; Pavesi, L.; Pucker, G.; Vanzetti, L. \& Bellutti, P. Electrical conduction and electroluminescence in nanocrystalline silicon based light emitting devices. Journal of applied physics, Vol.104, No.6, (September 2008), pp. 063103-063111, ISSN 1089-7550.

Prezioso, S.; Hossain, S. M.; Anopchenko, A.; Pavesi, L.; Wang, M.; Pucker, G. \& Bellutti, P. Superlinear photovoltaic effect in $\mathrm{Si}$ nanocrystals based metal-insulatorsemiconductor devices. Applied Physics Letters, Vol.94, No.6, (February 2009), pp. 062108-1-062108-3, ISSN 1077-3118.

Prokes, S.M.; Carlos, W.E.; Veprek, S. \& Ossadnik, Ch. Defect studies in as deposited and processed nanocrystalline $\mathrm{Si} / \mathrm{SiO}_{2}$ structures. Physical Review B, Vol.58, No.23, (December 1998), pp. 15632-15635, ISSN 1550-235X.

Pucker, G.; Bellutti, P.; Spinella, C.; Gatterer, K.; Cazzanelli, M. \& Pavesi, L. Room temperature luminescence from $\left(\mathrm{Si} / \mathrm{SiO}_{2}\right)_{\mathrm{n}} \mathrm{n}=1,2,3$ multilayers grown in an industrial low-pressure chemical vapour deposition reactor. Journal of Applied Physics, Vol.88, No.10, (November 2000) pp. 6044-6052, ISSN 1089-7550.

Richards, B.S. Luminescent layers for enhanced silicon solar cell performance: Downconversion. Solar Energy Materials and Solar Cells. Vol.90, No.9, (May 2006), pp.11891207, ISSN 0927-0248.

Richards, B.S. Enhancing the performance of silicon solar cells via the application of passive luminescence conversion layers. Solar Energy Materials and Solar Cells, Vol.90, No.15, (September 2006), pp. 2329-2337, ISSN 0927-0248.

Richards, B.S. \& McIntosh, K.R. Overcoming the poor short wavelength spectral response of CdS/CdTe photovoltaic modules via luminescence down-shifting: ray-tracing simulations, Progress in Photovoltaics, Vol.15, No.1, (January 2007), pp. 27-34, ISSN 1099-159X. 
Rinnert, H. \& Vergnat, M. Influence of the temperature on the photoluminescence of silicon clusters embedded in a silicon oxide matrix. Physica E, Vol.16, No.3-4, (March 2003), pp. 382-387, ISSN 1386-9477.

Ross, R.T. \& Nozik, A.J. Efficiency of hot-carrier solar energy converters. Journal of Applied Physics, Vol.53, No.5, (May 1982), pp. 3813-3819, ISSN 1089-7550.

Ruan, J.; Fauchet, P.M.; Dal Negro, L.; Cazzanelli, M. \& Pavesi, L. Stimulated emission in nanocrystalline silicon superlattices. Applied Physics Letters, Vol.83, No.26, (December 2003), pp. 5479-1-5479-3, ISSN 1077-3118.

van Sark, W.G.J.H.M.; Meijerink, A.; Schropp, R.E.I.; van Roosmalen, J.A.M. \& Lysen, E.H. Modeling improvement of spectral response of solar cells by deployment of spectral converters containing semiconductor nanocrystals. Semiconductors, Vol.38, No.8, (August 2004), pp. 962-969, ISSN 1090-6479.

Shaklee, K.L. \& Nahory, R.E. Valley-Orbit Splitting of Free Excitons? The Absorption Edge of Si. Physical Review Letters, Vol.24, No.17, (April 1970) pp. 942-945 ISSN 1079-7114.

Shockley, W. \& Queisser, H.J. Detailed Balance Limit of Efficiency of p-n Junction Solar Cells. Journal of Applied Physics, Vol.32, No.3, (March 1961), pp. 510-520, ISSN 10897550.

Shrestha, S.K.; Aliberti, P. \& Conibeer, G. Energy selective contacts for hot carrier solar cells. Solar Energy Materials and Solar Cells, Vol.94, No.9, (September 2010), pp. 1546-1550, ISSN 0927-0248.

Song, D.; Cho, E.C.; Conibeer, G.; Flynn, C.; Huang, Y. \& Green, M.A. Structural, electrical and photovoltaic characterization of Si nanocrystals embedded $\mathrm{SiC}$ matrix and $\mathrm{Si}$ nanocrystals/c-Si heterojunction devices. Solar Energy Materials and Solar Cells, Vol.92, No.4, (April 2008), pp. 474-481, ISSN 0927-0248.

Stegner, A.R.; Pereira, R.N.; Klein, K.; Lechner, R.; Dietmueller, R.; Brandt, M.S.; Stutzmann, M. \& Wiggers, H. Electronic Transport in Phosphorus-Doped Silicon Nanocrystal Networks. Physical review letters, Vol.100, No.2, (January 2008), pp. 026803-026807, ISSN 1079-7114.

Stupca, M.; Alsalhi, M.; Al Saud, T.; Almuhanna, A. \& Nayfeh, M.H. Enhancement of polycrystalline silicon solar cells using ultrathin films of silicon nanoparticle. Applied Physics Letters, Vol.91, No.6, (August 2007), pp. 063107-1-063107-3, ISSN 1077-3118.

Švrcek, V.; Slaoui, A. \& Muller, J.-C. Silicon nanocrystals as light converter for solar cells. Thin Solid Films, Vol.451-452, (March 2004), pp. 384-388, ISSN 0040-6090.

Švrcek, V.; Mariotti, D.; Shibata, Y.\& Kondo, M. A hybrid heterojunction based on fullerenes and surfactant-free, self-assembled, closely packed silicon nanocrystals. Journal of Physics D: Applied Physics. Vol.43, No.41, (October 2010), pp. 415402, ISSN 1361-6463.

Sychugov, I.; Juhasz, R.; Valenta, J. \& Linnros, J. Narrow Luminescence Linewidth of a Silicon Quantum Dot. Physical Review Letters, Vol.94, No.8, (March 2005), pp. 087405-087409, ISSN 1079-7114.

Takeda, Y.; Ito, T.; Motohiro, T.; König, D.; Shrestha, S. \& Conibeer, G. Hot carrier solar cells operating under practical conditions. Journal of Applied Physics, Vol.105, No.7, (July 2009), pp. 074905-074915, ISSN 1089-7550. 
Teske, S. \& Bitter, M. (2008). Solar Generation V-Solar electricity for over one billion people and two million jobs by 2020, Date of access: 10/09/11, Available from http://www.epia.org/S.

Trupke, T.; Green, M.A. \& Würfel, P. Improving solar cell efficiencies by down-conversion of high-energy photons. Journal of applied physics, Vol.92, No.3, (August 2002), pp. 1668-1675, ISSN 1089-7550.

Tsakalakos, L.; Balch, J.; Fronheiser, J.; Korevaar, B.A.; Sulima, O. \& Rand, J. Silicon nanowire solar cells. Applied Physics Letters, Vol.91, No.23, (December 2007), pp. 233117-1-233117-3, ISSN 1077-3118.

Tsybeskov, L.; Vandyshev, Ju.V. \& Fauchet, P.M. Blue emission in porous silicon: Oxygen related photoluminescence. Physical Review B, Vol.49, No.11, (March 1994), pp. 7821-7824, ISSN 1550-235X.

Uhlir, A. Electrolytic Shaping of Germanium and Silicon. Bell system Technical Journal, Vol.35, No.2, (March 1956), pp. 333-347, ISSN 0005-8580.

Umezu, I.; Yoshida, K.; Sugimura, A.; Inokuma, T.; Hasegawa, S.; Wakayama, Y.; Yamada, Y. \& Yoshida, T. A Comparative study of the photoluminescence properties of aSiOx:H film and silicon nanocrystallites. Journal of Non-Crystalline Solids, Vol.266269, No.2, (May 2000), pp. 1029-1032, ISSN 0022-3093.

Vinciguerra, V.; Franzò, G.; Priolo, F.; Iacona, F. \& Spinella, C. J. Quantum confinement and recombination dynamics in silicon nanocrystals embedded in $\mathrm{Si} / \mathrm{SiO}_{2}$ superlattices. Applied Physics, Vol.87, No.11, (June 2000), pp. 8165-8174, ISSN 1089-7550.

Wadia, C.; Alivisatos, A.P. \& Kammen, D.M. Materials Availability Expands the Opportunity for Large-Scale Photovoltaics Deployment. Environmental Science and Technology, Vol.43, No.6, (March 2009), pp. 2072-2077, ISSN 1520-5851.

Wan, Z.; Patterson, R.; Huang, S.; Green, M.A. \& Conibeer, G. Ultra-thin silicon nitride barrier implementation for $\mathrm{Si}$ nano-crystals embedded in amorphous silicon carbide matrix with hybrid superlattice structure. Europhysics letters, Vol.95, No.6, (September 2011), pp. 67006p1-67006p5, ISSN 1286-4854.

Wei, D.; Andrew, P. \& Ryhänen, T. Electrochemical photovoltaic cells-review of recent developments. Journal of Chemical Technology \& Biotechnology, Vol.85, No.12, (December 2010), pp. 1547-1552, ISSN 0142-0356.

Westland, D.J.; Ryan, J.F.; Scott, M.D.; Davies, J.I. \& Riffat, J.R. Hot carrier energy loss rates in GaInAs/InP quantum wells. Solid State Electronics, Vol.31, No.1-2, (March-April 1988), pp. 431-434, ISSN 0038-1101.

Wilson, W.L.; Szajowski, P.F. \& Brus, L.E. Quantum confinement in Size-selected, SurfaceOxidized Silicon Nanocrystals. Science, Vol.262, No.5137, (November 1993), pp. 1242-1244, ISSN 1095-9203.

Wolfsegger, C. \& Stierstorfer, J. (2007). Solar Generation IV 2007 - solar electricity for over one billion people and two million jobs by 2020, date of access 29/09/11, Available from: http://www.epia.org/fileadmin/EPIA_docs/publications/epia/EPIA_SG_IV_fin al.pdf.

Würfel, P. Solar energy conversion with hot electrons from impact ionisation. Solar Energy Materials and Solar Cells, Vol.46, No.1, (April 1997), pp. 43-52, ISSN 0927-0248. 
Würfel, P.; Brown, A.S.; Humphrey, T.E. \& Green, M.A. Particle conservation in the hotcarrier solar cell. Progress in Photovoltaics, Vol.13, No.4, (June 2005), pp. 277-285, ISSN 1099-159X.

Yang, C.S.; Lin, C.J.; Kuei, P.Y.; Horng, S.F.; Ching-Hsiang Hsu, C. \& Liaw, M.C. Quantum size effects on photoluminescence from Si nanocrystals in PECVD silicon-richoxide. Applied Surface Science, Vol.113/114, (April 1997), pp. 116-120, ISSN 01694332.

Zatryb, G.; Podhorodecki, A.; Hao, X.J.; Misiewicz, J.; Shen, Y.S. \& Green, M.A. Quantitative evaluation of boron-induced disorder in multilayers containing silicon nanocrystals in an oxide matrix designed for photovoltaic applications. Optics express, Vol.18, No.21, (October 2010), pp. 22004-22009, ISSN 1094-4087.

Zatryb, G.; Podhorodecki, A.; Hao, X.J.; Misiewicz, J.; Shen, Y.S. \& Green, M.A. Correlation between stress and carrier nonradiative recombination for silicon nanocrystals in oxide matrix. Nanotechnology, Vol.22, No.33, (August 2011), pp. 335703-335708, ISSN 1361-6528. 


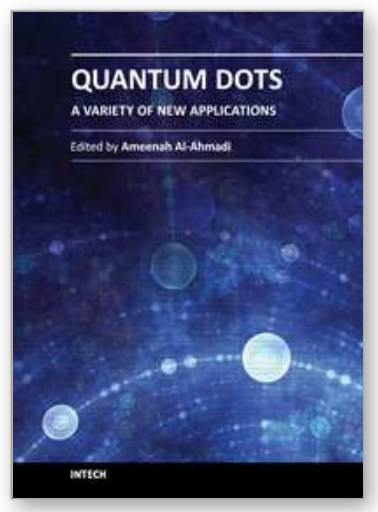

\section{Quantum Dots - A Variety of New Applications}

Edited by Dr. Ameenah Al-Ahmadi

ISBN 978-953-51-0483-4

Hard cover, 280 pages

Publisher InTech

Published online 04, April, 2012

Published in print edition April, 2012

The book "Quantum dots: A variety of a new applications" provides some collections of practical applications of quantum dots. This book is divided into four sections. In section 1 a review of the thermo-optical characterization of CdSe/ZnS core-shell nanocrystal solutions was performed. The Thermal Lens (TL) technique was used, and the thermal self-phase Modulation (TSPM) technique was adopted as the simplest alternative method. Section 2 includes five chapters where novel optical and lasing application are discussed. In section 3 four examples of quantum dot system for different applications in electronics are given. Section 4 provides three examples of using quantum dot system for biological applications. This is a collaborative book sharing and providing fundamental research such as the one conducted in Physics, Chemistry, Biology, Material Science, Medicine with a base text that could serve as a reference in research by presenting up-todate research work on the field of quantum dot systems.

\section{How to reference}

In order to correctly reference this scholarly work, feel free to copy and paste the following:

Georg Pucker, Enrico Serra and Yoann Jestin (2012). Silicon Quantum Dots for Photovoltaics: A Review, Quantum Dots - A Variety of New Applications, Dr. Ameenah Al-Ahmadi (Ed.), ISBN: 978-953-51-0483-4, InTech, Available from: http://www.intechopen.com/books/quantum-dots-a-variety-of-new-applications/siliconquantum-dots-for-photovoltaics

\section{INTECH}

open science | open minds

\section{InTech Europe}

University Campus STeP Ri

Slavka Krautzeka 83/A

51000 Rijeka, Croatia

Phone: +385 (51) 770447

Fax: +385 (51) 686166

www.intechopen.com

\section{InTech China}

Unit 405, Office Block, Hotel Equatorial Shanghai

No.65, Yan An Road (West), Shanghai, 200040, China

中国上海市延安西路65号上海国际贵都大饭店办公楼 405 单元

Phone: +86-21-62489820

Fax: $+86-21-62489821$ 
(C) 2012 The Author(s). Licensee IntechOpen. This is an open access article distributed under the terms of the Creative Commons Attribution 3.0 License, which permits unrestricted use, distribution, and reproduction in any medium, provided the original work is properly cited. 